NASA

Technical

Paper

3293

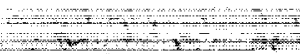

December 1992

Emittance Measurements

of Space Shuttle Orbiter

Reinforced Carbon-Carbon

Jose M. Caram,

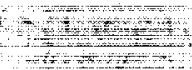

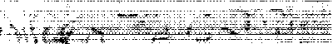

$\frac{10}{2}=$

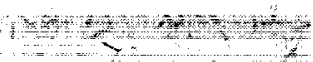

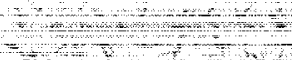

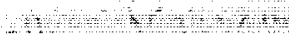
WWE W

$\frac{x}{4}=-4$

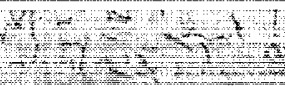

Stanley A. Bouslog,

and George R. Cunnington, Jr.

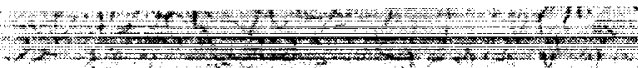

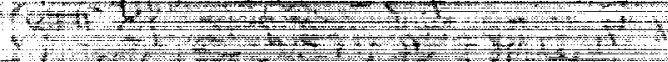

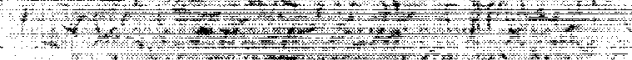

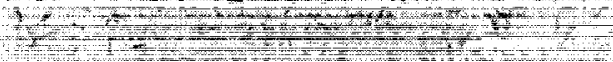

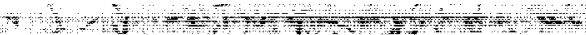

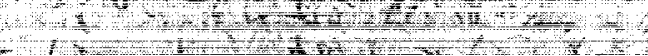

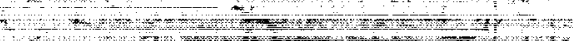

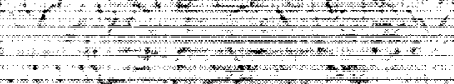

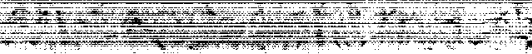

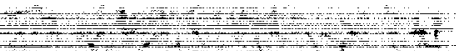


NASA

Technical

Paper

3293

1992

\section{Emittance Measurements of Space Shuttle Orbiter Reinforced Carbon-Carbon}

Jose M. Caram

Lyndon B. Johnson Space Center

Houston, Texas

Stanley A. Bouslog

Lockheed Engineering \& Sciences Company

Houston, Texas

George R. Cunnington, Jr.

Lockheed Palo Alto Research Laboratory

Palo Alto, California
National Aeronautics and Space Administration

Office of Management Scientific and Technical Information Program 


\title{
ERRATA
}

NASA Technical Paper 3293

\section{Emittance Measurements of Space Shuttle Orbiter Reinforced Carbon-Carbon}

\author{
Jose M. Caram, Stanley A. Bouslog, \\ and George R. Cunningham, Jr.
}

December 1992

Pages 1 and 2: Text has been rearranged.

Page 15: Right-hand side of figure 1 is missing.

Please replace pages 1,2 , and 15 with the attached new pages.

Issue date: February 25, 1993 


\section{CONTENTS}

Section

Page

ABSTRACT

INTRODUCTION

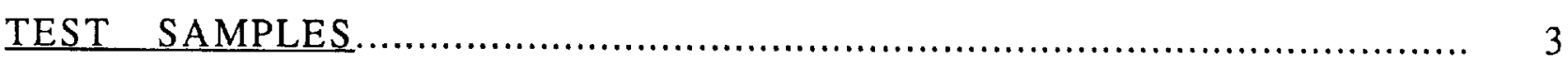

TEST DESCRIPTION ...................................................................... 3

TEST RESULTS

Room Temperature Reflectance Data ............................................... 4

High Temperature Emittance Data ...................................................... 5

High Temperature Total Normal and Total Hemispherical Emittance ..................... 6

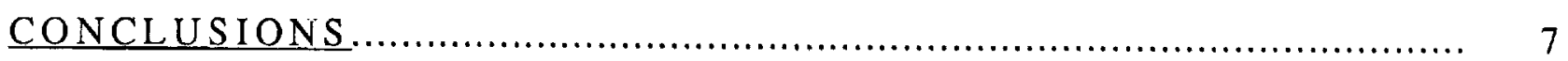

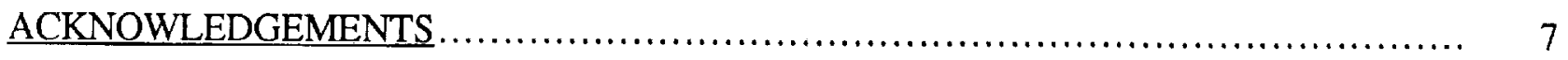

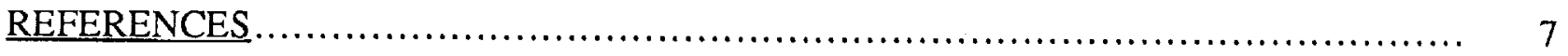




\section{TABLES}

Table

Page

Virgin RCC Room Temperature Normal Emittance....................... 9

Virgin RCC Sample 4 Room Temperature Directional Emittance ............. 10

Virgin RCC Sample 5 Room Temperature Directional Emittance

Virgin and Flown RCC Samples Room Temperature Normal

Emittance.

Virgin RCC Spectral Hemispherical Emittance ........................... 11

Virgin RCC Sample 4 Spectral Normal Emittance ........................ 11

Virgin RCC Sample 5 Spectral Normal Emittance

Flown RCC Outer 1 Spectral Normal Emittance ........................... 12

Flown RCC Outer 2 Spectral Normal Emittance .

Flown RCC Inner 1 Spectral Normal Emittance.. 


\section{FIGURES}

Figure

Page

1

2

$3 \mathrm{~A}$

$3 B$

$3 \mathrm{C}$

3D

4

5

6

7

8

9

10

Sketch of Scanning Broadband Radiometer Test Setup at Lockheed Palo Alto Research Laboratory....

Spectral Near-Normal Emittance at Room Temperature for Virgin RCC

Room Temperature Directional Emittance Data for Virgin RCC Samples

Room Temperature Directional Emittance Data for Virgin RCC Samples

Room Temperature Directional Emittance Data for Virgin RCC Samples

Room Temperature Directional Emittance Data for Virgin RCC Samples

Virgin and Flown RCC Spectral Normal Emittance at Room Temperature.

High Temperature Near-Normal Spectral Emittance Data for Virgin RCC

(a) Virgin Sample 4

(b) Virgin Sample 5

High Temperature Near-Normal Spectral Emittance Data for Flown RCC

(a) Flown RCC - Outer Surface - Sample 1.................................. 20

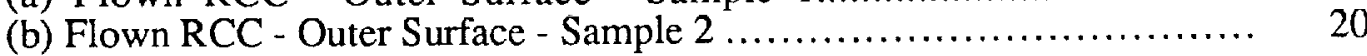

High Temperature Near-Normal Spectral Emittance Data for Flown RCC

(a) Flown RCC - Inner Surface - Sample 1 ........................... 21

(b) Flown RCC - Inner Surface - Sample 2................................. 21

High Temperature Total Normal Emittance Data for flown RCC

Samples

(a) Flown RCC - Inner Surface ........................................ 22

(b) Flown RCC - Outer Surface ..................................... 22

Comparison of High Temperature Total Normal Emittance.................. 23

Comparison of High Temperature Total Normal Emittance.................. 23 


\begin{abstract}
The spectral and total normal emittance of the Reinforced Carbon-Carbon (RCC) used on Space Shuttle Orbiter nose cap and wing leading edges has been measured at room temperature and at surface temperatures of 1200 to $2100^{\circ} \mathrm{K}$. These measurements were made on virgin and two flown RCC samples. Room temperature directional emittance data were also obtained and were used to determine the total hemispherical emittance of RCC as a function of temperature. Results of the total normal emittance for the virgin samples showed good agreement with the current RCC emittance design curve; however, the data from the flown samples showed an increase in the emittance at high temperature possibly due to exposure from flight environments.
\end{abstract}




\section{Introduction}

The Space Shuttle Orbiter was the first operational hypersonic reentry vehicle flown with a nonablating reusable thermal protection system. The Leading Edge Sub-System (LESS) of the Orbiter, which includes the nose cap and wing leading edges, is protected from the extreme heat of reentry by the use of Reinforced Carbon-Carbon (RCC). RCC is a carbon composite possessing reasonable strength and low coefficient of thermal expansion which provides it with excellent resistance to thermal stress and shock. 1 The carboncarbon is protected from oxidation by tetraethyl-ortho silicate (TEOS) impregnation and a silicon carbide (SiC) outer coating. The silicon carbide coating has a high total hemispherical emittance at normal operating temperatures around $1800^{\circ} \mathrm{K}$ which enhances the radiative heat rejection from the surface. However, under more severe conditions the emittance of the silicon carbide coating has been shown ${ }^{2}$ to decrease as surface temperatures increase. Because of the effect the emittance of the silicon carbide coating has on the amount of heat transfer that the RCC surfaces are exposed to, accurate information on the variance of the total hemispherical emittance as a function of temperature of the SiC coating on the RCC is required.

Local heat transfer to the surface by convection under hypersonic flight conditions is determined from an energy balance, where heat addition is from the boundary layer heating and heat rejection is by radiation from the surface and conduction through the RCC. The accuracy of the determination of hot wall convective heat flux from flight or arc-plasma heated hypersonic wind tunnel data is directly dependent on the accuracy of the absolute value of the total hemispherical emittance of the coating at the temperature of the surface. The lower emittance would result in higher surface temperatures to maintain radiation equilibrium.

Since this thermal protection system is reusable, it is also of interest to evaluate changes in emittance with exposure to the hypersonic flight environment. Two RCC specimens were obtained from the right side wing panel $17 \mathrm{~T}$-seal of the Space Shuttle Orbiter Atlantis. These specimens were cut from the T-seal at the location of the flow stagnation region. In this region, the heating to the wing panel during entry is at a maximum. In order to compare the data from the flown specimens and emittance data which was previously obtained, ${ }^{2}$ virgin RCC samples were also tested. The present report summarizes the test procedures and test data including a determination of the total hemispherical emittance of the RCC/SiC coating as a function of temperature.

\section{Test Samples}

As was previously mentioned, two flown RCC samples (1 and 2) and two virgin RCC samples (4 and 5) were tested for emittance variation from room temperature to $2100^{\circ} \mathrm{K}$. The flown samples were obtained from the 
right side wing panel $17 \mathrm{~T}$-seal on the Orbiter Atlantis (OV-104). The T-seal had been flown on nine Space Shuttle missions. The samples were cut in $4.5 \mathrm{~cm} \times 2.5 \mathrm{~cm}$ sections, $0.64 \mathrm{~cm}$ thick, from the stagnation region of the panel. The stagnation region is the hottest portion of the T-seal during entry of the Orbiter. In order to perform the high temperature tests, these samples were further reduced to nominal dimensions of $1.2 \mathrm{~cm} \times 1.2$ $\mathrm{cm}$. The virgin samples, obtained from LTV Corporation, were circular disks $1.9 \mathrm{~cm}$ in diameter and $0.64 \mathrm{~cm}$ in thickness. Two of the virgin samples were instrumented with a tungsten-5\%-rhenium/tungsten-26\%rhenium thermocouple mounted along the centerline and placed just below the $\mathrm{SiC}$ coating. The thermocouples provided secondary surface temperature measurement support to the optical pyrometers.

\section{Test Description}

A Cary Model 17 Spectroflectometer was used to measure the room temperature near normal (6 degrees off normal) reflectance of the flown samples at wavelengths from 0.28 to 2.2 micrometers, whereas a Gier-Dunkle Model SP250 integrating sphere spectrophotometer was used for the virgin samples for wavelengths from 0.3 to 2.5 micrometers. At wavelengths between 2 and 25 micrometers, the reflectance was measured using the Gier-Dunkle Model HC-300 Heated Cavity Reflectometer. With this instrumentation, directional spectral reflectance data were obtained from near $0^{\circ}$ to $75^{\circ}$. More details about this apparatus are provided in Ref. 3. Maximum uncertainty in spectral reflectance is typically \pm 0.01 .

Data at temperatures ranging from 1200 to $2100^{\circ} \mathrm{K}$ were obtained using the Lockheed Missiles and Space Company (LMSC) Scanning Broadband Radiometer (SBR), ${ }^{4}$ with the front surface of the test sample heated with a continuous wave $\mathrm{CO}_{2}$ laser in air at a pressure of $4.9 \mathrm{kPa}$ (37 Torr). The incident irradiance was uniform to within 5 percent over a $2 \mathrm{~cm}$ diameter spot at the center of the specimen. The SBR viewed a 0.8 $\mathrm{cm}$ diameter region centered in the area of uniform laser irradiation. A sketch of this test setup, along with the location from which the flown samples were taken, is shown in Figure 1. The filter wheel used has positions for eight filters which provided spectral data at wavelengths of $1.0,2.08,2.4,2.73,3.65,4.76,5.35$, and 6.3 micrometers. Surface temperature of the sample was determined with optical pyrometers ( 0.65 and 4.5 micrometers). The SBR was calibrated using a high temperature blackbody over the range of 1100 to $2400^{\circ} \mathrm{K}$ to establish a correlation between the pyroelectric detector signal and radiant intensity. The estimated maximum uncertainty in the SBR data is $\mathbf{\pm 0 . 0 4}$. 


\section{Test Results}

\section{Room Temperature Reflectance Data}

Near-normal spectral reflectance data at room temperature were obtained for two of the virgin RCC samples (4 and 5). Since the room temperature transmittance of the SiC coating is low, the reflectance can be related to emittance (Emittance $=1$ - Reflectance). Near-normal emittance as a function of wavelength ( 0.28 to 25 micrometers) is presented in Figure 2 and Table 1 . The dip in the emittance at 10 to 13 micrometers is characteristic of the reststrahlen bands of the silicon carbide material. 5 Spectral directional emittance data for these samples for wavelengths varying from 0.5 to 16 micrometers are shown in Figure 3. The data show good agreement between the two samples over the viewing angles and wavelengths tested. At the lower wavelengths, 0.5 to 2.0 micrometers, the emittance decreases slightly at the higher viewing angles indicating a small degree of specularity. However for the higher wavelengths, 4.0 to 16 micrometers, the emittance of the RCC/SiC coating begins to increase at the $60^{\circ}$ viewing angle. It can also be seen that for the 10 to 16 micrometer range the emittance begins to spread, indicating the diffuse nature of the material at these higher wavelengths. Tables 2 and 3 also provide the directional emittance data.

Room temperature spectral normal reflectance values for both the inner and outer surfaces of the flown RCC samples, as well as data for the virgin samples over the same range, are shown in Figure 4 and in Table 4. The limited wavelength range of the data for the flown samples was due to the unsuitability of the samples to be machined to the size required by the HC300 instrument. The spectral normal emittance of the flown samples inner and outer surfaces is substantially higher than the virgin samples emittance at the 0.5 micrometer wavelength before converging at 1.5 micrometers. The fairly constant emittance, approximately 0.92 , of the flown samples over the wavelength range tested may be an indication of the effect of repeated exposure to flight temperatures. The slight difference between the inner and outer surfaces in the visible and near IR wavelengths is well within the experimental error listed in this report.

Total normal emittance data at room temperature for the virgin and flown samples were determined by integrating the spectral data. Recall that the room temperature data for the flown specimen were limited from 0.4 micrometers to 2.2 micrometers and that there was good agreement at the higher wavelength with the virgin samples, Figure 4 . Therefore, the total normal room temperature emittance of the flown samples outer and inner surfaces was found by assuming that the variation of the spectral emittance above the 2.2 micrometer wavelength was similar to the average of the virgin samples. Thus, the total normal emittance could be found for the flown samples for wavelengths between 0.4 
and 24 micrometers. For virgin samples 4 and 5 the total normal room temperature emittance was 0.847 and 0.858 respectively, whereas for the flown specimen there was very little change between the outer and inner surfaces; they were 0.856 and 0.857 , respectively.

Room temperature total hemispherical emittance for the virgin samples was obtained by integrating the directional emittance data (Fig. 3) for each of the wavelengths. This integration results in a ratio of hemispherical to normal emittance for each wavelength. These ratios were multiplied by the normal emittance for each wavelength and then integrated again over the wavelength band. Integration of the directional data for each wavelength was done from $0^{\circ}$ to $90^{\circ}$ and results in a ratio of hemispherical to normal emittance. If the data were obtained primarily between $20^{\circ}$ and $75^{\circ}$, the emittance was assumed constant between $0^{\circ}$ and $20^{\circ}$, and to have a cosine variation between the last angle and $90^{\circ}$. As a result, the ratios of hemispherical to normal emittance for each wavelength varied between 0.912 and 0.972 , and hemispherical emittance totals at room temperature for virgin samples 4 and 5 were found to be 0.824 and 0.851 , respectively. These data are summarized in Table 5.

\section{High Temperature Emittance Data}

Spectral normal emittance values for SiC coating from the two instrumented virgin samples and the two flown samples, both inner and outer surfaces, were also measured at surface temperatures of approximately 1200 to $2100^{\circ} \mathrm{K}$ with the SBR. Figures $5 \mathrm{a}$ and $5 \mathrm{~b}$ and Tables 6 and 7 present the spectral normal emittance for virgin samples 4 and 5 , respectively. The general trends of the high temperature spectral data are consistent with those reported by Wakefield 6 for Arc-Jet results at a temperature of $2000^{\circ} \mathrm{K}$. For both samples, a slight dip in the emittance can be seen in the 2 to 3 micrometer region with a strong decrease at 6 micrometers. At temperatures above $1900^{\circ} \mathrm{K}$, a marked decrease in the emittance can be seen over the range of wavelengths. Indications of this decrease begin to appear at the 1 and 6 micrometer wavelengths when the temperature reaches approximately $1500^{\circ} \mathrm{K}$. The spectral normal emittance data of the outer surface of the flown RCC samples (1 and 2) are seen in Figures $6 \mathrm{a}$ and $6 \mathrm{~b}$, respectively. The data show trends which are similar to those of the virgin samples. However, the dip between the 2 to 3 micrometer region is no Ionger discernible. Also, as surface temperatures increase, the decrease in the emittance for all wavelengths presented is less for the flown samples as compared to the virgin sample data. Both of these effects may be attributed to repeated exposure to flight reentry environments. These data are also provided in Table 8.

In Figures 7a and $7 \mathrm{~b}$ and Table 9, the spectral normal emittance data for the inner surface of the flown specimens can be seen. There is little spectral dependence of the emittance of the inner surface and variation of spectral emittance with temperature is much less than that of the outer surface 
measurements. Of particular interest in the figure is the lack of falloff above the 6 micrometer wavelength when compared to the virgin and flown specimen. In order to understand this insensitivity, emittance data for uncoated carbon-carbon 7 are used for comparison. The agreement between the current data and the uncoated carbon-carbon indicates that there has been some modification of the $\mathrm{SiC}$ coating, which is typically between $0.051 \mathrm{~cm}$ and $0.1 \mathrm{~cm}$ in thickness, on the inner surface of the flown specimen. This modification may be due to either contact between the inner side of the T-seal and the RCC panel when they are exposed to the thermal and pressure stresses of flight, which may reduce the $\mathrm{SiC}$ coating thickness, or to the deposition of particulate from the various outgassing materials inside the wing leading edge cavity. Further analysis of the inner surface of the $\mathrm{T}$-seal is required in order to determine this source.

\section{High Temperature Total Normal and Total Hemispherical Emittance}

Total normal emittance data were also obtained from the SBR tests. Figure 8a shows the total normal emittance of the inner surface of the flown RCC samples. Also included in the figure are the data for the uncoated carbon-carbon material which again shows that a modification of the SiC coating has occurred. The inner surface emittance data are essentially independent of temperature over the test temperature range, with an average value of 0.76 . Unlike the inner surface data, the outer surface total normal emittance data for both flown specimens, seen in Figure 8b, decreases from a value of 0.86 at $1350^{\circ} \mathrm{K}$ to 0.75 at $2050^{\circ} \mathrm{K}$. However, when compared to the virgin emittance data and the LTV design curve, ${ }^{2}$ Figure 9 , the total normal emittance for the outer surface of the flown RCC with the SiC coating shows excellent agreement except at the highest surface temperature test condition of $2050^{\circ} \mathrm{K}$. At this temperature, the emittance for both flown specimens increases to 0.75 as compared to 0.63 for the virgin samples with an error of \pm 0.04 . The increase in the emittance at this high temperature is beneficial in reducing the amount of heat energy absorbed into the material. The total normal data are also provided in Tables 10 and 11.

The total hemispherical emittance, which is the material property value needed for heat transfer computations, was computed from the test data by multiplying the total normal high temperature emittance values by the ratio of total hemispherical to total normal emittance for each of the samples obtained from the room temperature reflectance data. The use of these ratios for the high temperature hemispherical emittance values assumes that the directional distribution of emittance does not change with temperature. The total hemispherical emittance for the virgin and the flown $\mathrm{RCC} / \mathrm{SiC}$ samples as a function of temperature are presented in Figure 10 and Table 12. Although slightly lower in magnitude than the total normal data, the flown outer surface data again show good agreement with the virgin samples except at the highest surface temperature test condition. The increase in the emittance at 
the higher temperatures is believed to be caused by repeated exposure to flight environments and more flown samples should be obtained to verify this result.

\section{Conclusions}

Emittance tests have been conducted on both virgin and flown samples of RCC with a SiC coating. Room temperature spectral and directional reflectance measurements were obtained. Normal spectral and total emittance values have also been obtained for surface temperatures from 1200 to $2050^{\circ} \mathrm{K}$. Total hemispherical emittance data at these temperatures were determined by assuming that the variation of the ratio of hemispherical to normal emittance data was constant with respect to temperature. The total normal emittance for the virgin material decreases from 0.89 to 0.63 over this temperature range. Using the room temperature directional data, the total hemispherical emittance data varied from 0.87 to 0.613 . Comparable emittance values were measured for the flown RCC samples at the lower temperatures, but the emittance only decreased to 0.75 for the total normal and to 0.72 for the total hemispherical at the higher temperatures. This trend suggests that the entry flight environment has affected the emittance characteristics of the RCC/SiC coating. However, only a limited amount of data was obtained at the high temperatures and further tests would be required to confirm this trend.

\section{Acknowledgements}

The authors would like to thank Dr. Don Curry and Christopher Madden of the Thermal Analysis Section at NASA - Johnson Space Center for obtaining the flown RCC samples.

\section{References}

1. Curry, D. M., and Webster, C. N.; "Material Characteristics of Space Shuttle Reinforced CarbonCarbon," 24th National SAMPE Symposium, San Francisco, California, May 8-10, 1979.

2. Webster, C. N.; "LESS-Avtex Rayon RCC Qualification Emissivity Test Results," LTV Dir. No. 3-56700/AVTEX/0-0001, July 25, 1990.

3. Dunkle, R. V., Edwards, D. K., Gier, R., et al; "Heated Cavity Reflectometer for Angular Reflectance Measurements," Progress in International Research on Thermodynamic and Transport Properties, ASME, New York, 1962, pp. 541-562. 
4. Olstad, S. J. and Cunnington, G. R.; "Evaluation of a Multiband Infrared Radiometer," AIAA-880075, Presented at the 26th AIAA Aerospace Sciences Meeting, Reno, Nevada, 1988.

5. Handbook of Optics, McGraw-Hill Book Co., 1978, pp. 8-97.

6. Wakefield, R. M., "Surface Emissivity of Reinforced Carbon Composite with an OxidationInhibiting Coating," NASA TMX-61,351, October, 1973.

7. LMSC Report TP-7602, "High Temperature Emittance Test Results for Two Carbon-Carbon Samples," August 26, 1991. 
Table 1 - Virgin RCC Room Temperature Normal Emittance

\begin{tabular}{|c|c|c|c|c|c|}
\hline $\begin{array}{c}\text { Wavelength } \\
(\mu \mathrm{m})\end{array}$ & Sample 4 & Sample 5 & $\begin{array}{c}\text { Wavelength } \\
(\mu \mathrm{m})\end{array}$ & Sample 4 & Sample 5 \\
\hline 0.300 & 0.810 & 0.820 & 11.5 & 0.762 & 0.770 \\
0.500 & 0.792 & 0.813 & 12.0 & 0.719 & 0.732 \\
0.800 & 0.832 & 0.834 & 12.5 & 0.693 & 0.709 \\
0.900 & 0.842 & 0.843 & 13.0 & 0.770 & 0.788 \\
1.00 & 0.868 & 0.873 & 13.5 & 0.794 & 0.812 \\
1.20 & 0.889 & 0.890 & 14.0 & 0.803 & 0.820 \\
1.50 & 0.900 & 0.910 & 14.5 & 0.808 & 0.825 \\
1.75 & 0.910 & 0.911 & 15.0 & 0.812 & 0.830 \\
2.00 & 0.918 & 0.919 & 15.5 & 0.815 & 0.830 \\
2.50 & 0.929 & 0.928 & 16.0 & 0.818 & 0.835 \\
3.00 & 0.937 & 0.936 & 16.5 & 0.816 & 0.830 \\
3.50 & 0.938 & 0.938 & 17.0 & 0.812 & 0.832 \\
4.00 & 0.937 & 0.937 & 17.5 & 0.818 & 0.832 \\
4.50 & 0.935 & 0.935 & 18.0 & 0.812 & 0.832 \\
5.00 & 0.930 & 0.933 & 18.5 & 0.811 & 0.828 \\
5.50 & 0.926 & 0.928 & 19.0 & 0.820 & 0.838 \\
6.00 & 0.924 & 0.928 & 19.5 & 0.810 & 0.827 \\
6.50 & 0.912 & 0.914 & 20.0 & 0.818 & 0.836 \\
7.00 & 0.912 & 0.914 & 20.5 & 0.812 & 0.830 \\
7.50 & 0.910 & 0.913 & 21.0 & 0.810 & 0.832 \\
8.00 & 0.911 & 0.916 & 21.5 & 0.803 & 0.825 \\
8.50 & 0.908 & 0.915 & 22.0 & 0.805 & 0.825 \\
9.00 & 0.895 & 0.912 & 22.5 & 0.801 & 0.820 \\
9.50 & 0.892 & 0.910 & 23.0 & 0.808 & 0.827 \\
10.0 & 0.909 & 0.913 & 23.5 & 0.811 & 0.828 \\
10.5 & 0.862 & 0.863 & 24.0 & 0.827 & 0.833 \\
11.0 & 0.808 & 0.812 & & & \\
\hline & & & & & \\
\hline
\end{tabular}


Table 2 - Virgin RCC Sample 4 Room Temperature Directional Emittance

\begin{tabular}{|c|c|c|c|c|c|c|c|c|c|}
\hline $\begin{array}{l}\text { View } \\
\text { Angle }\end{array}$ & $0.5 \mu \mathrm{m}$ & $1.0 \mu \mathrm{m}$ & $1.5 \mu \mathrm{m}$ & $2.0 \mu \mathrm{m}$ & $4.0 \mu \mathrm{m}$ & $7.0 \mu \mathrm{m}$ & $10 \mu \mathrm{m}$ & $13 \mu \mathrm{m}$ & $16 \mu \mathrm{m}$ \\
\hline $0^{\circ}$ & 0.790 & 0.868 & 0.900 & 0.917 & & & & & \\
$20^{\circ}$ & 0.798 & 0.870 & 0.900 & 0.915 & 0.938 & 0.913 & 0.911 & 0.775 & 0.822 \\
$30^{\circ}$ & 0.790 & 0.867 & 0.900 & 0.915 & 0.935 & 0.910 & 0.910 & 0.772 & 0.820 \\
$40^{\circ}$ & 0.775 & 0.860 & 0.896 & 0.912 & 0.937 & 0.910 & 0.906 & 0.770 & 0.805 \\
$50^{\circ}$ & 0.763 & 0.851 & 0.888 & 0.905 & 0.932 & 0.904 & 0.900 & 0.762 & 0.801 \\
$60^{\circ}$ & 0.755 & 0.848 & 0.880 & 0.899 & 0.928 & 0.902 & 0.893 & 0.760 & 0.812 \\
$65^{\circ}$ & & & & & 0.928 & 0.906 & 0.896 & 0.775 & \\
$70^{\circ}$ & 0.742 & 0.832 & 0.870 & 0.888 & & & & & \\
$75^{\circ}$ & 0.738 & 0.828 & 0.855 & 0.870 & & & & & \\
\hline
\end{tabular}

Table 3 - Virgin RCC Sample 5 Room Temperature Directional Emittance

\begin{tabular}{|c|c|c|c|c|c|c|c|c|c|}
\hline $\begin{array}{c}\text { View } \\
\text { Angle }\end{array}$ & $0.5 \mu \mathrm{m}$ & $1.0 \mu \mathrm{m}$ & $1.5 \mu \mathrm{m}$ & $2.0 \mu \mathrm{m}$ & $4.0 \mu \mathrm{m}$ & $7.0 \mu \mathrm{m}$ & $10 \mu \mathrm{m}$ & $13 \mu \mathrm{m}$ & $16 \mu \mathrm{m}$ \\
\hline $0^{\circ}$ & 0.813 & 0.875 & 0.903 & 0.918 & & & & & \\
$20^{\circ}$ & 0.811 & 0.875 & 0.903 & 0.916 & 0.938 & 0.915 & 0.920 & 0.796 & 0.838 \\
$30^{\circ}$ & 0.810 & 0.870 & 0.901 & 0.916 & 0.938 & 0.915 & 0.918 & 0.795 & 0.835 \\
$40^{\circ}$ & 0.805 & 0.865 & 0.900 & 0.914 & 0.937 & 0.915 & 0.918 & 0.794 & 0.830 \\
$50^{\circ}$ & 0.800 & 0.863 & 0.897 & 0.912 & 0.932 & 0.910 & 0.912 & 0.787 & 0.825 \\
$60^{\circ}$ & 0.790 & 0.858 & 0.892 & 0.910 & 0.928 & 0.910 & 0.911 & 0.780 & 0.821 \\
$65^{\circ}$ & & & & & 0.935 & 0.915 & 0.912 & 0.790 & 0.828 \\
$70^{\circ}$ & 0.781 & 0.848 & 0.880 & 0.900 & 0.940 & 0.915 & 0.915 & 0.796 & 0.838 \\
$75^{\circ}$ & 0.770 & 0.840 & & 0.891 & & & & & \\
\hline
\end{tabular}

Table 4 - Virgin and Flown RCC Samples Room Temperature Normal Emittance

\begin{tabular}{|c|c|c|c|c|}
\hline $\begin{array}{c}\text { Wavelength } \\
(\mu \mathrm{m})\end{array}$ & Sample 4 & Sample 5 & $\begin{array}{c}\text { Flown Outer } \\
\text { Surface }\end{array}$ & $\begin{array}{c}\text { Flown Inner } \\
\text { Surface }\end{array}$ \\
\hline 0.400 & 0.810 & 0.820 & 0.911 & 0.931 \\
0.500 & 0.792 & 0.814 & 0.912 & 0.925 \\
0.700 & 0.832 & 0.835 & 0.912 & 0.923 \\
0.800 & 0.842 & 0.844 & 0.911 & 0.922 \\
1.00 & 0.868 & 0.875 & 0.915 & 0.930 \\
1.20 & 0.888 & 0.890 & 0.918 & 0.930 \\
1.50 & 0.900 & 0.910 & 0.920 & 0.930 \\
1.70 & 0.910 & 0.912 & 0.921 & 0.932 \\
2.00 & 0.918 & 0.918 & 0.925 & 0.934 \\
2.20 & 0.922 & 0.922 & 0.922 & 0.934 \\
\hline
\end{tabular}


Table 5 - Virgin RCC Spectral Hemispherical Emittance

\begin{tabular}{|c|c|c|c|c|c|c|}
\hline \multirow{2}{*}{$\begin{array}{c}\text { Wavelength } \\
(\mu \mathrm{m})\end{array}$} & \multicolumn{3}{|c|}{ Sample 4 } & \multicolumn{3}{c|}{ Sample 5 } \\
\cline { 2 - 7 } & $\begin{array}{c}\text { Normal } \\
\text { Emittance }\end{array}$ & $\begin{array}{c}\text { Hemis./ } \\
\text { Normal }\end{array}$ & $\begin{array}{c}\text { Hemis. } \\
\text { Emittance }\end{array}$ & $\begin{array}{c}\text { Normal } \\
\text { Emittance }\end{array}$ & $\begin{array}{c}\text { Hemis./ } \\
\text { Normal }\end{array}$ & $\begin{array}{c}\text { Hemis. } \\
\text { Emittance }\end{array}$ \\
\hline 0.500 & 0.792 & 0.954 & 0.756 & 0.813 & 0.969 & 0.788 \\
1.00 & 0.868 & 0.965 & 0.838 & 0.873 & 0.969 & 0.846 \\
1.50 & 0.900 & 0.968 & 0.871 & 0.910 & 0.949 & 0.864 \\
2.00 & 0.918 & 0.966 & 0.887 & 0.919 & 0.972 & 0.893 \\
4.00 & 0.937 & 0.939 & 0.880 & 0.937 & 0.962 & 0.901 \\
7.00 & 0.912 & 0.939 & 0.856 & 0.914 & 0.963 & 0.880 \\
10.0 & 0.909 & 0.937 & 0.852 & 0.913 & 0.966 & 0.882 \\
13.0 & 0.770 & 0.942 & 0.725 & 0.788 & 0.968 & 0.763 \\
16.0 & 0.818 & 0.912 & 0.746 & 0.835 & 0.959 & 0.801 \\
\hline
\end{tabular}

Table 6 - Virgin RCC Sample 4 Spectral Normal Emittance

\begin{tabular}{|c|c|c|c|c|c|}
\hline $\begin{array}{c}\text { Wavelength } \\
(\mu \mathrm{m})\end{array}$ & $1354^{\circ} \mathrm{K}$ & $1504^{\circ} \mathrm{K}$ & $1770^{\circ} \mathrm{K}$ & $1915^{\circ} \mathrm{K}$ & $2037^{\circ} \mathrm{K}$ \\
\hline 1.00 & 0.850 & 0.830 & 0.700 & 0.600 & 0.550 \\
2.08 & 0.890 & 0.870 & 0.840 & 0.740 & 0.620 \\
2.40 & 0.850 & 0.810 & 0.790 & 0.730 & 0.670 \\
2.73 & & & 0.930 & 0.840 & 0.710 \\
3.65 & 0.910 & 0.900 & 0.870 & 0.810 & 0.740 \\
4.76 & 0.870 & 0.820 & 0.790 & 0.750 & 0.720 \\
5.35 & 0.850 & 0.790 & 0.770 & 0.690 & 0.630 \\
6.30 & 0.625 & & 0.410 & 0.430 & 0.440 \\
\hline
\end{tabular}

Table 7 - Virgin RCC Sample 5 Spectral Normal Emittance

\begin{tabular}{|c|c|c|c|c|}
\hline $\begin{array}{c}\text { Wavelength } \\
(\mu \mathrm{m})\end{array}$ & $1367^{\circ} \mathrm{K}$ & $1506^{\circ} \mathrm{K}$ & $1690^{\circ} \mathrm{K}$ & $1772^{\circ} \mathrm{K}$ \\
\hline 1.00 & 0.840 & 0.810 & 0.740 & 0.680 \\
2.08 & & & 0.820 & 0.810 \\
2.40 & 0.850 & 0.830 & 0.840 & 0.800 \\
2.73 & 0.930 & & 0.880 & 0.910 \\
3.65 & 0.900 & & 0.910 & 0.890 \\
4.76 & 0.870 & 0.810 & 0.830 & 0.800 \\
5.35 & & & 0.800 & 0.750 \\
6.30 & 0.700 & 0.470 & 0.480 & 0.400 \\
\hline
\end{tabular}


Table 8A - Flown RCC Outer 1 Spectral Normal Emittance

\begin{tabular}{|c|c|c|c|c|}
\hline $\begin{array}{c}\text { Wavelength } \\
(\mu \mathrm{m})\end{array}$ & $1384^{\circ} \mathrm{K}$ & $1583^{\circ} \mathrm{K}$ & $1724^{\circ} \mathrm{K}$ & $2050^{\circ} \mathrm{K}$ \\
\hline 1.00 & 0.810 & 0.770 & 0.750 & 0.690 \\
2.08 & 0.830 & & 0.790 & 0.720 \\
2.40 & 0.860 & 0.880 & 0.780 & 0.740 \\
2.73 & 0.855 & 0.790 & 0.800 & 0.760 \\
3.65 & 0.860 & 0.890 & 0.840 & 0.760 \\
4.76 & 0.825 & 0.780 & 0.760 & 0.730 \\
5.35 & 0.805 & 0.780 & 0.760 & 0.730 \\
6.30 & 0.500 & 0.540 & 0.530 & 0.440 \\
\hline
\end{tabular}

Table 8B - Flown RCC Outer 2 Spectral Normal Emittance

\begin{tabular}{|c|c|c|c|c|}
\hline $\begin{array}{c}\text { Wavelength } \\
(\mu \mathrm{m})\end{array}$ & $1368^{\circ} \mathrm{K}$ & $1562^{\circ} \mathrm{K}$ & $1701^{\circ} \mathrm{K}$ & $2053^{\circ} \mathrm{K}$ \\
\hline 1.00 & 0.780 & 0.750 & 0.740 & 0.700 \\
2.08 & 0.790 & 0.780 & 0.760 & 0.740 \\
2.40 & 0.850 & 0.890 & 0.790 & \\
2.73 & 0.880 & 0.850 & 0.740 & 0.770 \\
3.65 & & & 0.830 & 0.740 \\
4.76 & 0.750 & & 0.760 & 0.780 \\
5.35 & & & 0.750 & \\
6.30 & 0.450 & & 0.530 & 0.500 \\
\hline
\end{tabular}

Table 9A - Flown RCC Inner 1 Spectral Normal Emittance

\begin{tabular}{|c|c|c|c|c|}
\hline $\begin{array}{c}\text { Wavelength } \\
(\mu \mathrm{m})\end{array}$ & $1357^{\circ} \mathrm{K}$ & $1550^{\circ} \mathrm{K}$ & $1770^{\circ} \mathrm{K}$ & $1989^{\circ} \mathrm{K}$ \\
\hline 1.00 & 0.730 & 0.760 & 0.740 & \\
2.08 & & 0.770 & 0.730 & \\
2.40 & & 0.730 & & 0.710 \\
2.73 & & & 0.720 & 0.700 \\
3.65 & 0.770 & 0.740 & 0.750 & 0.730 \\
4.76 & 0.770 & 0.750 & 0.760 & 0.700 \\
5.35 & & 0.710 & 0.715 & 0.695 \\
6.30 & 0.620 & 0.650 & & 0.645 \\
\hline
\end{tabular}


Table 9B - Flown RCC Inner 2 Spectral Normal Emittance

\begin{tabular}{|c|c|c|c|c|}
\hline $\begin{array}{c}\text { Wavelength } \\
(\mu \mathrm{m})\end{array}$ & $1423^{\circ} \mathrm{K}$ & $1611^{\circ} \mathrm{K}$ & $1759^{\circ} \mathrm{K}$ & $2153^{\circ} \mathrm{K}$ \\
\hline 1.00 & 0.720 & 0.780 & 0.740 & 0.700 \\
2.08 & & 0.795 & 0.700 & 0.760 \\
2.40 & 0.740 & & 0.750 & \\
2.73 & & & 0.730 & \\
3.65 & 0.780 & & 0.750 & 0.730 \\
4.76 & 0.780 & & 0.770 & 0.700 \\
5.35 & 0.730 & 0.720 & 0.740 & 0.700 \\
6.30 & 0.650 & 0.670 & 0.640 & 0.600 \\
\hline
\end{tabular}

Table 10 - Flown RCC Total Normal Emittance

\begin{tabular}{|c|c|c|c|c|c|c|c|}
\hline $\begin{array}{c}\text { Temp. } \\
\left({ }^{\circ} \mathrm{K}\right)\end{array}$ & $\begin{array}{c}\text { Inner } \\
\text { Surface 1 }\end{array}$ & $\begin{array}{c}\text { Temp. } \\
\left({ }^{\circ} \mathrm{K}\right)\end{array}$ & $\begin{array}{c}\text { Inner } \\
\text { Surface 2 }\end{array}$ & $\begin{array}{c}\text { Temp. } \\
\left({ }^{\circ} \mathrm{K}\right)\end{array}$ & $\begin{array}{c}\text { Outer } \\
\text { Surface 1 }\end{array}$ & $\begin{array}{c}\text { Temp. } \\
\left({ }^{\circ} \mathrm{K}\right)\end{array}$ & $\begin{array}{c}\text { Outer } \\
\text { Surface 2 }\end{array}$ \\
\hline 1358.0 & 0.770 & 1420.0 & 0.770 & 1380.0 & 0.875 & 1370.0 & 0.840 \\
1550.0 & 0.760 & 1610.0 & 0.765 & 1580.0 & 0.785 & 1565.0 & 0.790 \\
1770.0 & 0.735 & 1760.0 & 0.755 & 1722.0 & 0.825 & 1700.0 & 0.800 \\
1990.0 & 0.730 & 2150.0 & 0.735 & 2050.0 & 0.740 & 2057.0 & 0.760 \\
\hline
\end{tabular}

Table 11 - Composite Total Normal Emittance for RCC

\begin{tabular}{|c|c|c|c|c|c|}
\hline Temp. $\left({ }^{\circ} \mathrm{K}\right)$ & LTV Design & Temp. $\left({ }^{\circ} \mathrm{K}\right)$ & Virgin & Temp. $\left({ }^{\circ} \mathrm{K}\right)$ & $\begin{array}{c}\text { Flown } \\
\text { Outer }\end{array}$ \\
\hline 533.00 & 0.825 & 300.0 & 0.853 (avg.) & 300.0 & 0.856 \\
756.00 & 0.863 & 1205.0 & 0.890 & 1370.0 & 0.840 \\
1033.0 & 0.890 & 1350.0 & 0.870 & 1380.0 & 0.875 \\
1200.0 & 0.900 & 1360.0 & 0.840 & 1565.0 & 0.790 \\
1311.0 & 0.900 & 1505.0 & 0.830 & 1580.0 & 0.785 \\
1422.0 & 0.880 & 1505.0 & 0.810 & 1700.0 & 0.800 \\
1589.0 & 0.833 & 1670.0 & 0.800 & 1722.0 & 0.825 \\
1756.0 & 0.770 & 1695.0 & 0.770 & 2050.0 & 0.740 \\
1922.0 & 0.694 & 1760.0 & 0.750 & 2057.0 & 0.760 \\
2089.0 & 0.610 & 1770.0 & 0.790 & & \\
& & 1910.0 & 0.670 & & \\
& & 1915.0 & 0.700 & & \\
\hline
\end{tabular}


Table 12 - Composite Total Hemispherical Emittance for RCC

\begin{tabular}{|c|c|c|c|}
\hline Temp. $\left({ }^{\circ} \mathrm{K}\right)$ & Virgin & Temp. $\left({ }^{\circ} \mathrm{K}\right)$ & $\begin{array}{c}\text { Flown } \\
\text { Outer }\end{array}$ \\
\hline 1205.0 & 0.86600 & 1370.0 & 0.82200 \\
1350.0 & 0.84700 & 1380.0 & 0.85600 \\
1360.0 & 0.83300 & 1565.0 & 0.77300 \\
1505.0 & 0.80400 & 1580.0 & 0.76800 \\
1505.0 & 0.80800 & 1700.0 & 0.78200 \\
1670.0 & 0.77800 & 1722.0 & 0.80700 \\
1695.0 & 0.76400 & 2050.0 & 0.72400 \\
1760.0 & 0.74400 & 2057.0 & 0.74300 \\
1770.0 & 0.76900 & & \\
1910.0 & 0.66500 & & \\
1915.0 & 0.68100 & & \\
2040.0 & 0.61300 & & \\
\hline
\end{tabular}




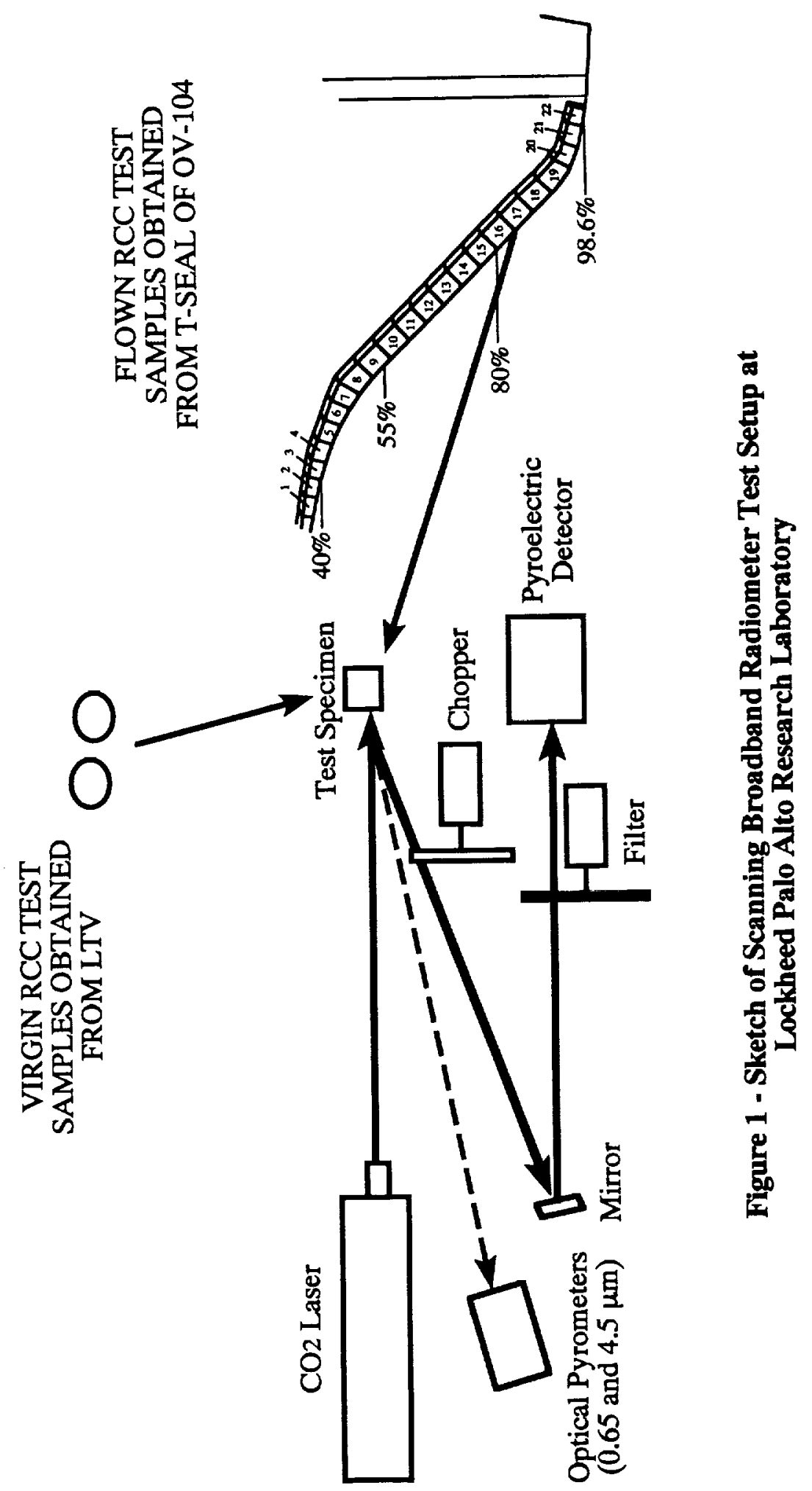




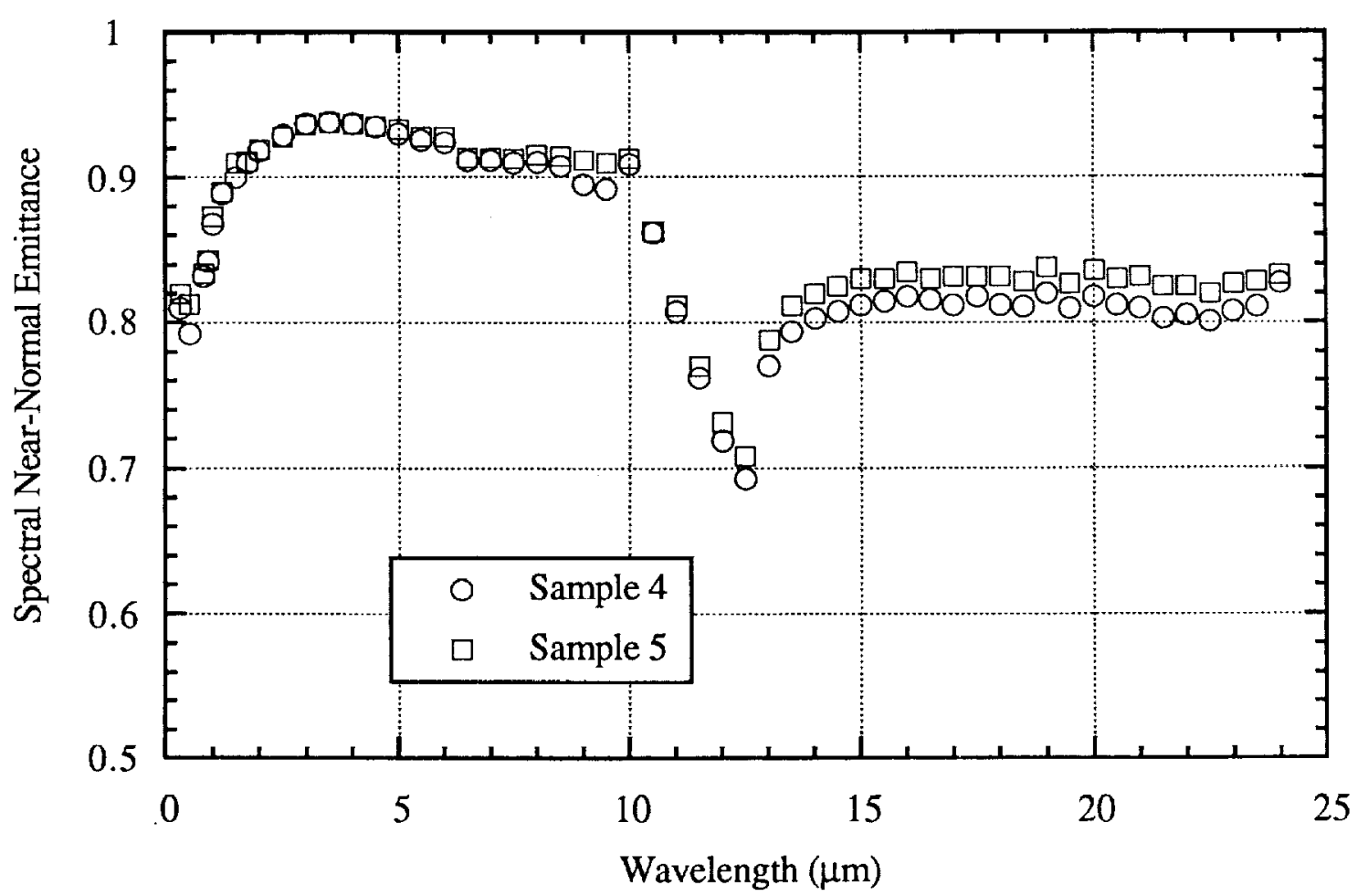

Figure 2 - Spectral Near-Normal Emittance at Room Temperature for Virgin RCC

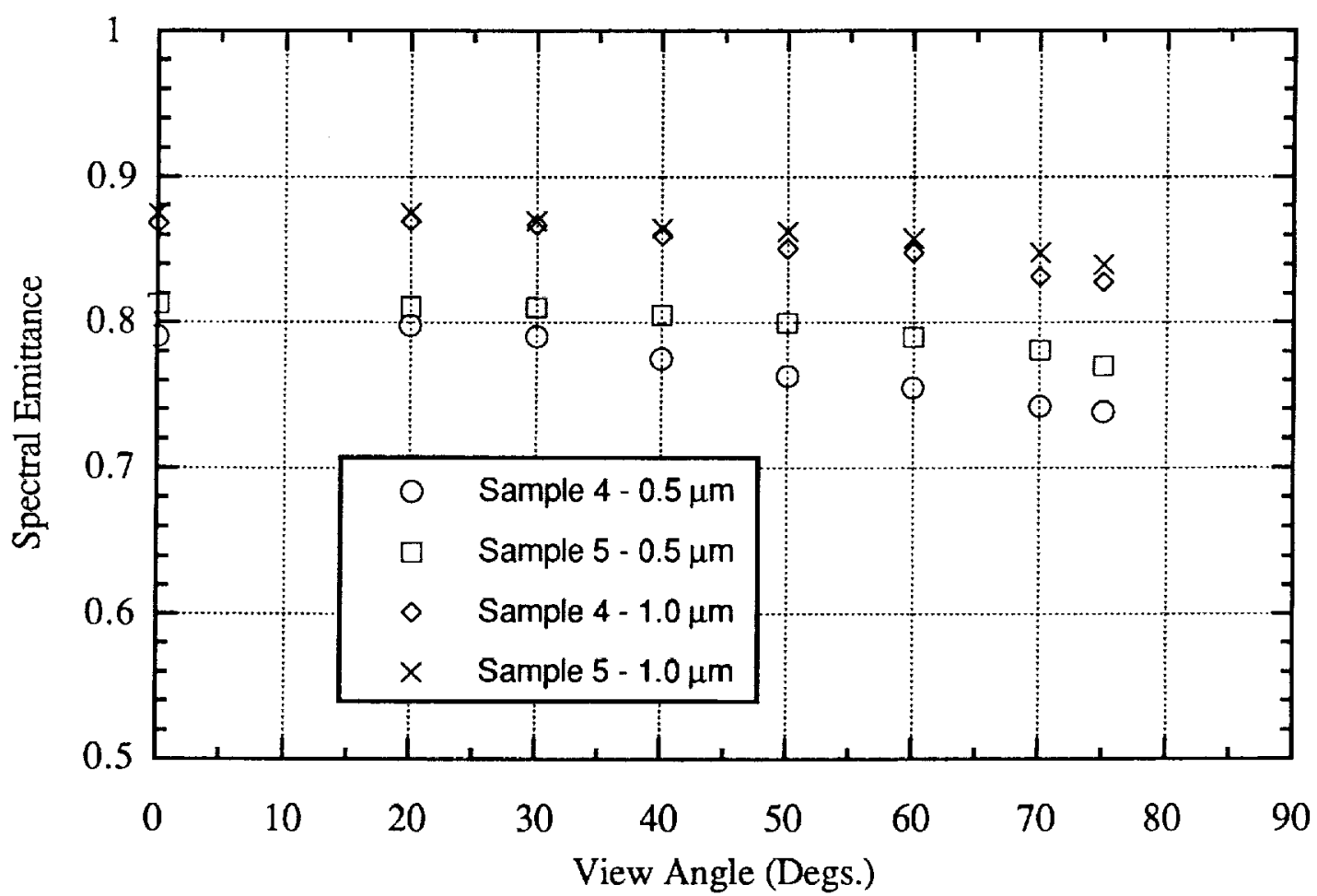

Figure 3A - Room Temperature Directional Emittance Data for Virgin RCC Samples 


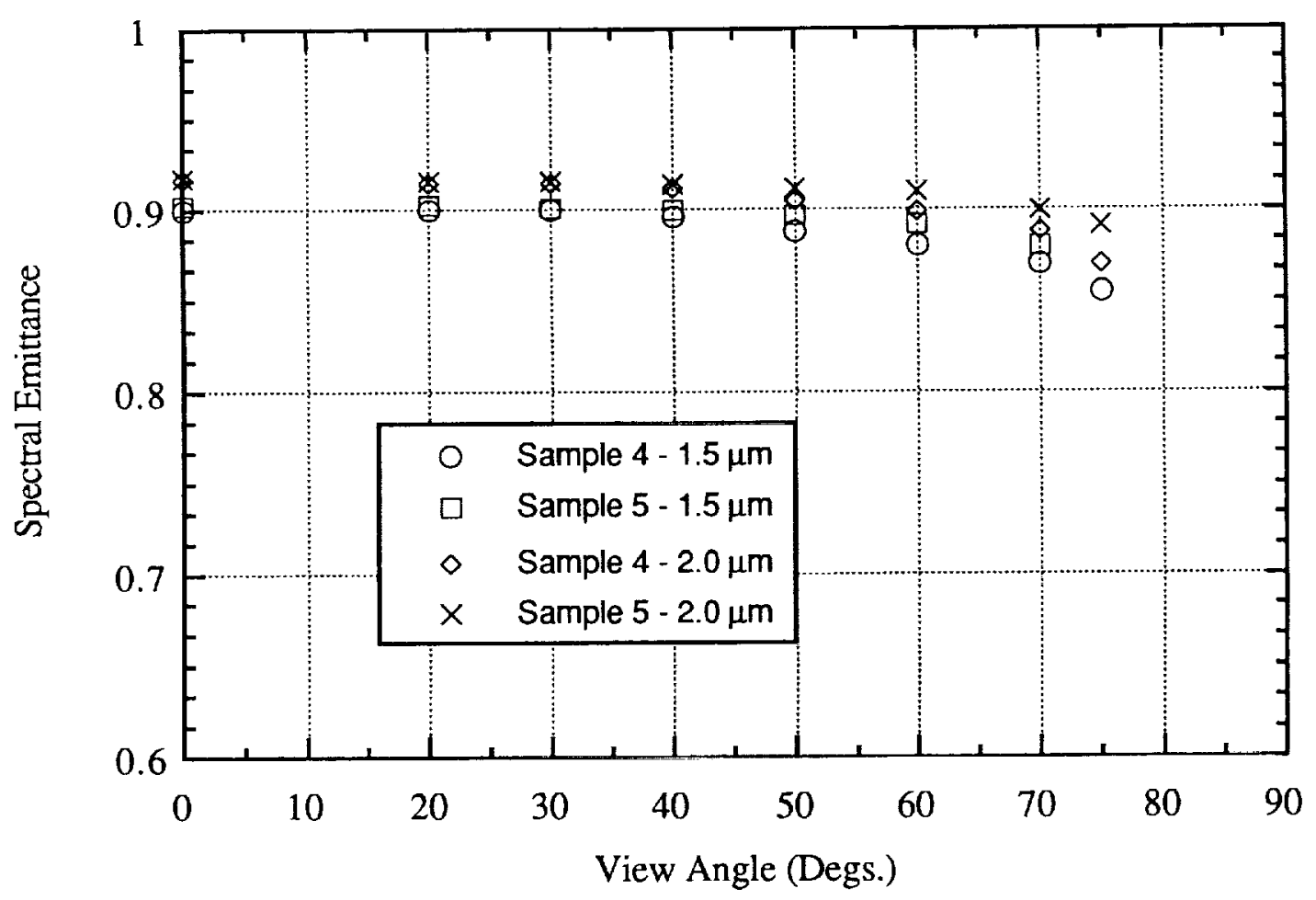

Figure 3B - Room Temperature Directional Emittance Data for Virgin RCC Samples

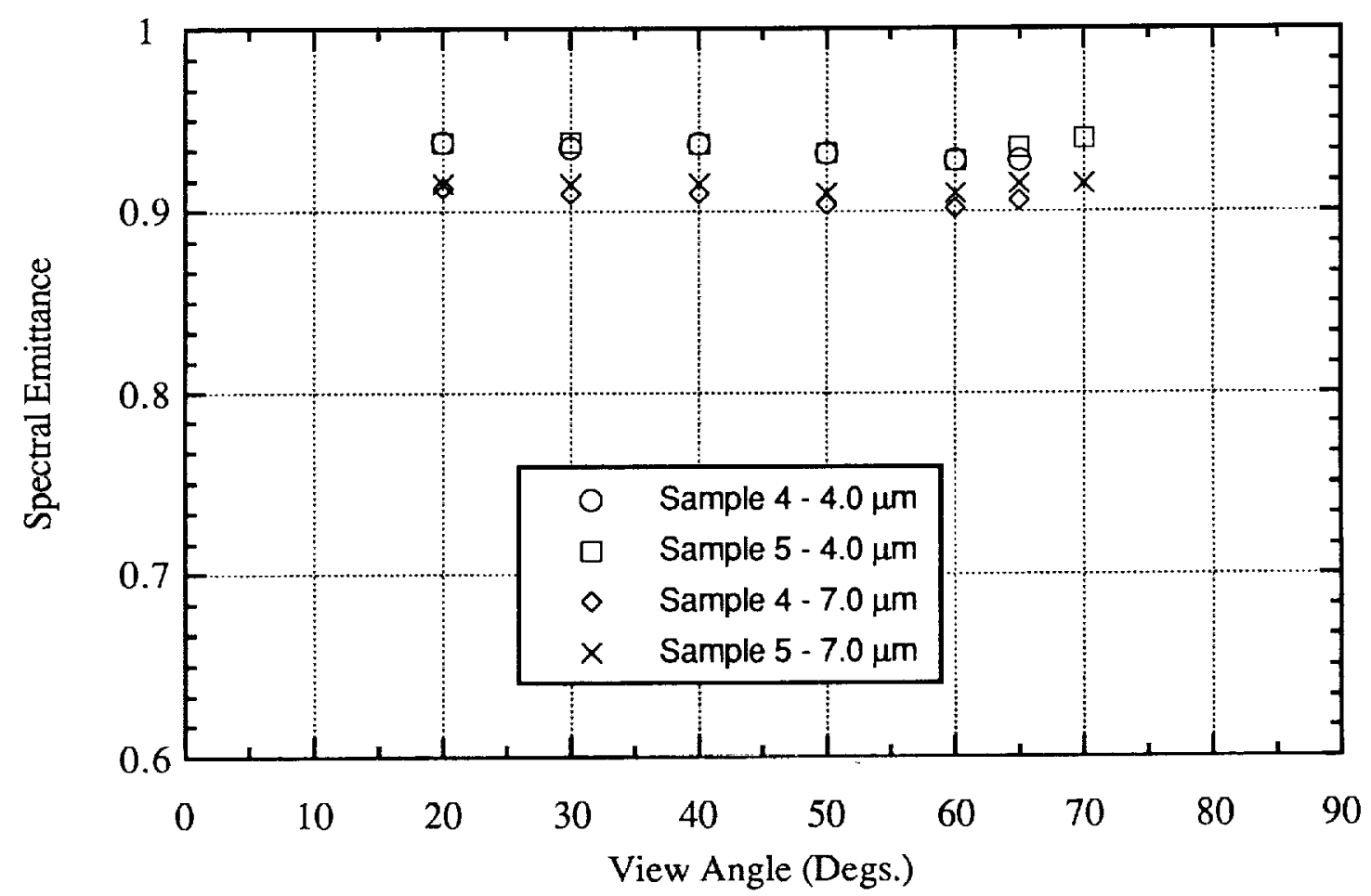

Figure 3C - Room Temperature Directional Emittance Data for Virgin RCC Samples 


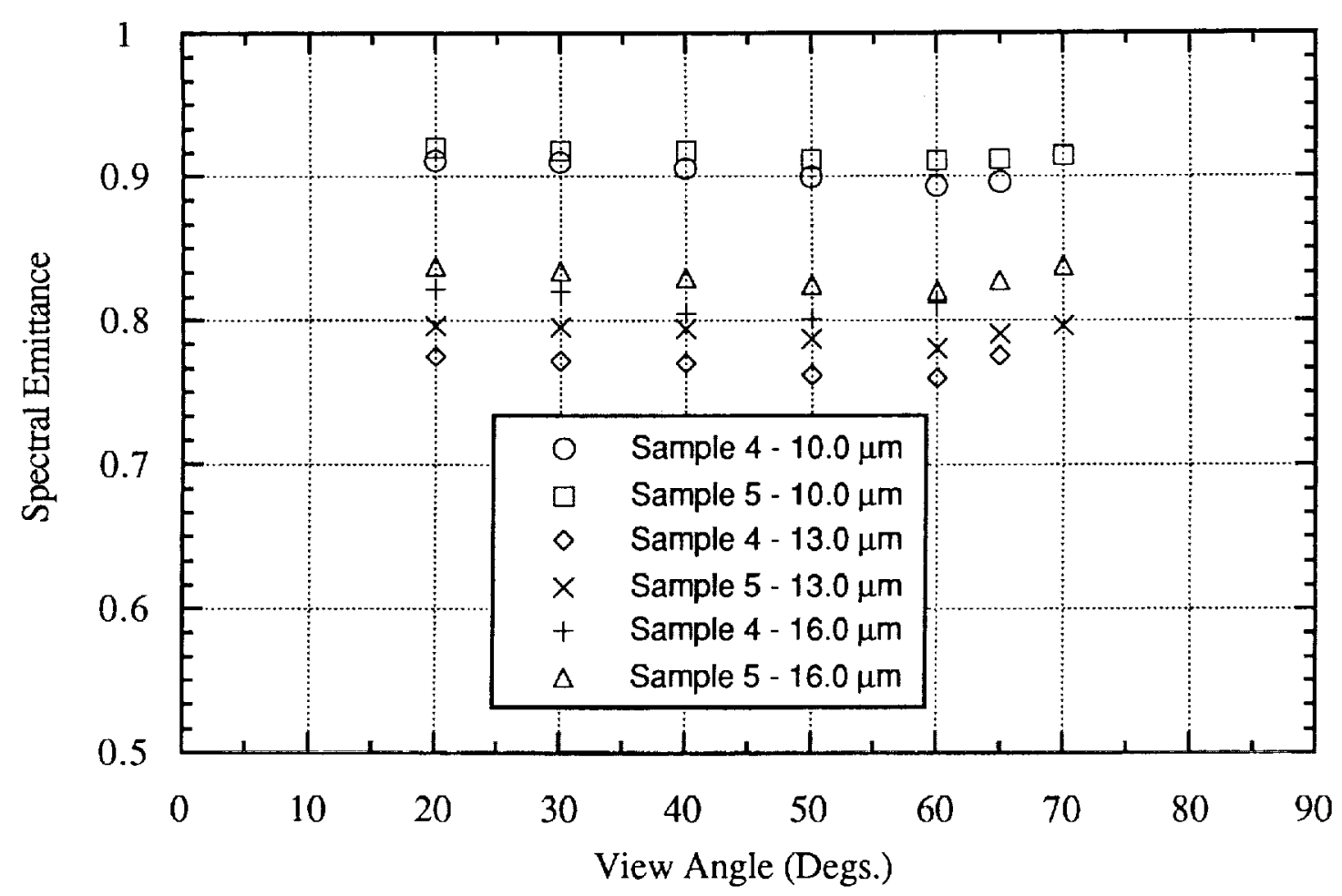

Figure 3D - Room Temperature Directional Emittance Data for Virgin RCC Samples

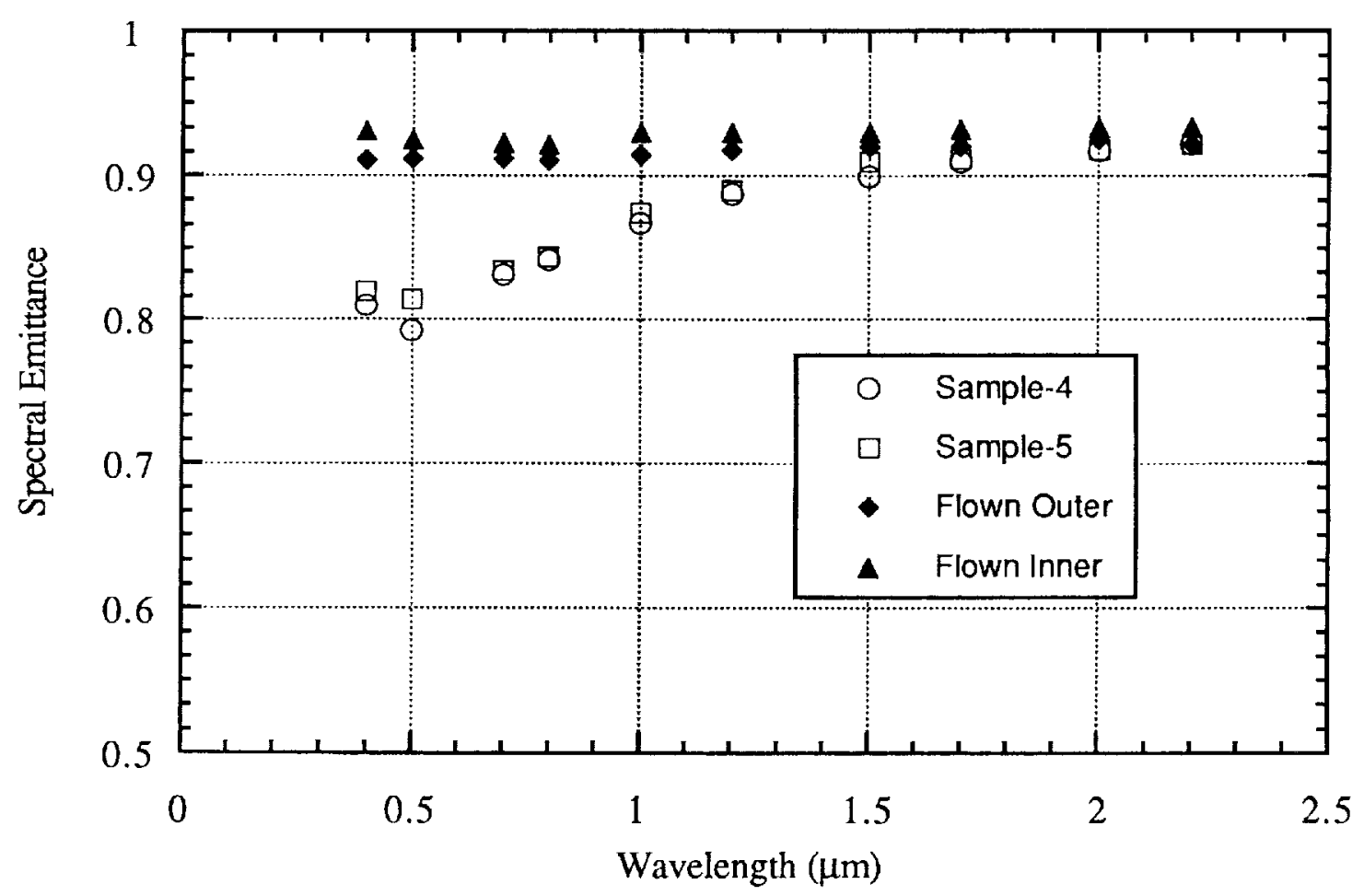

Figure 4 - Virgin and Flown RCC Spectral Normal Emittance at Room Temperature 


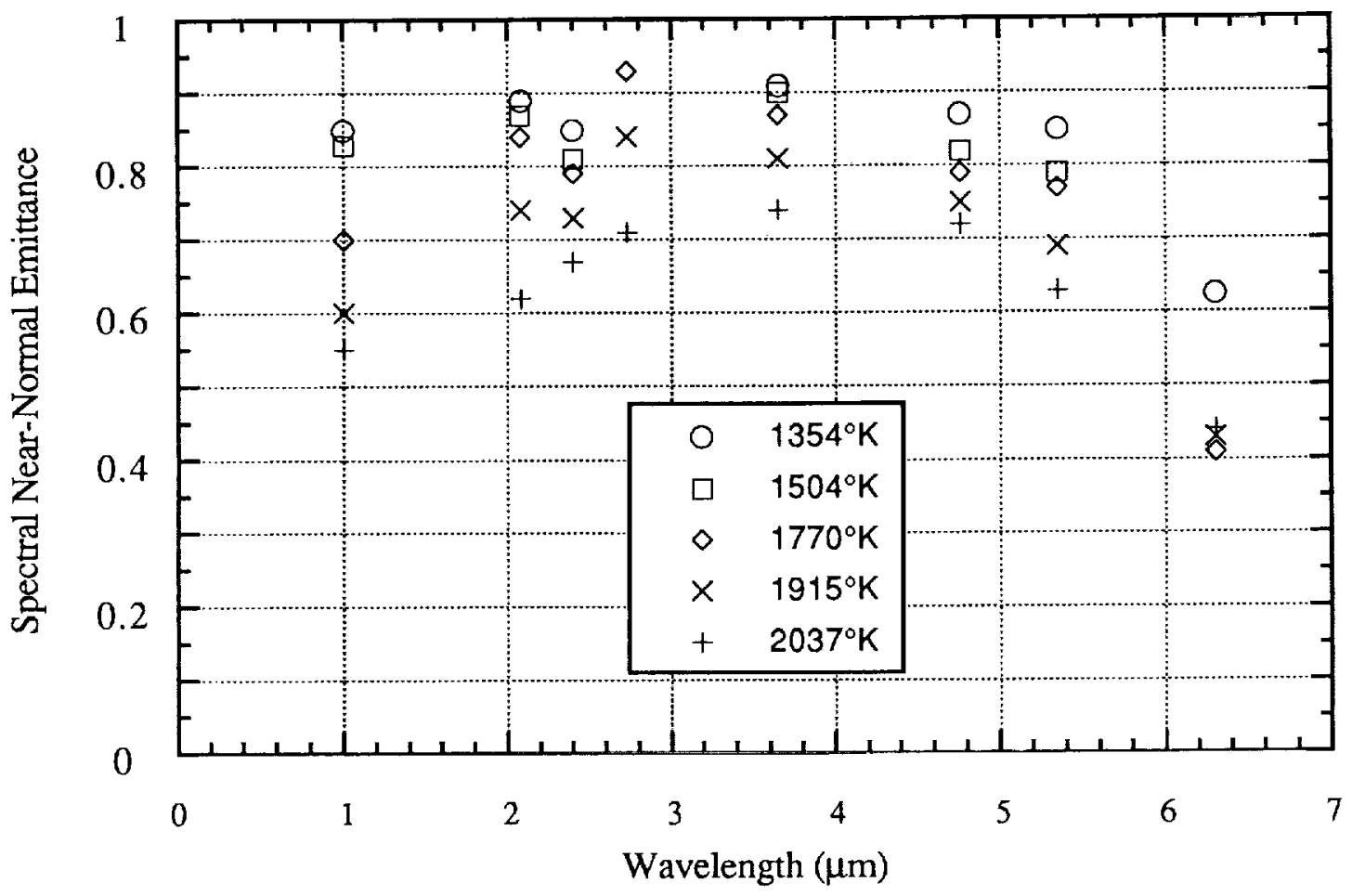

(5A) Virgin Sample 4

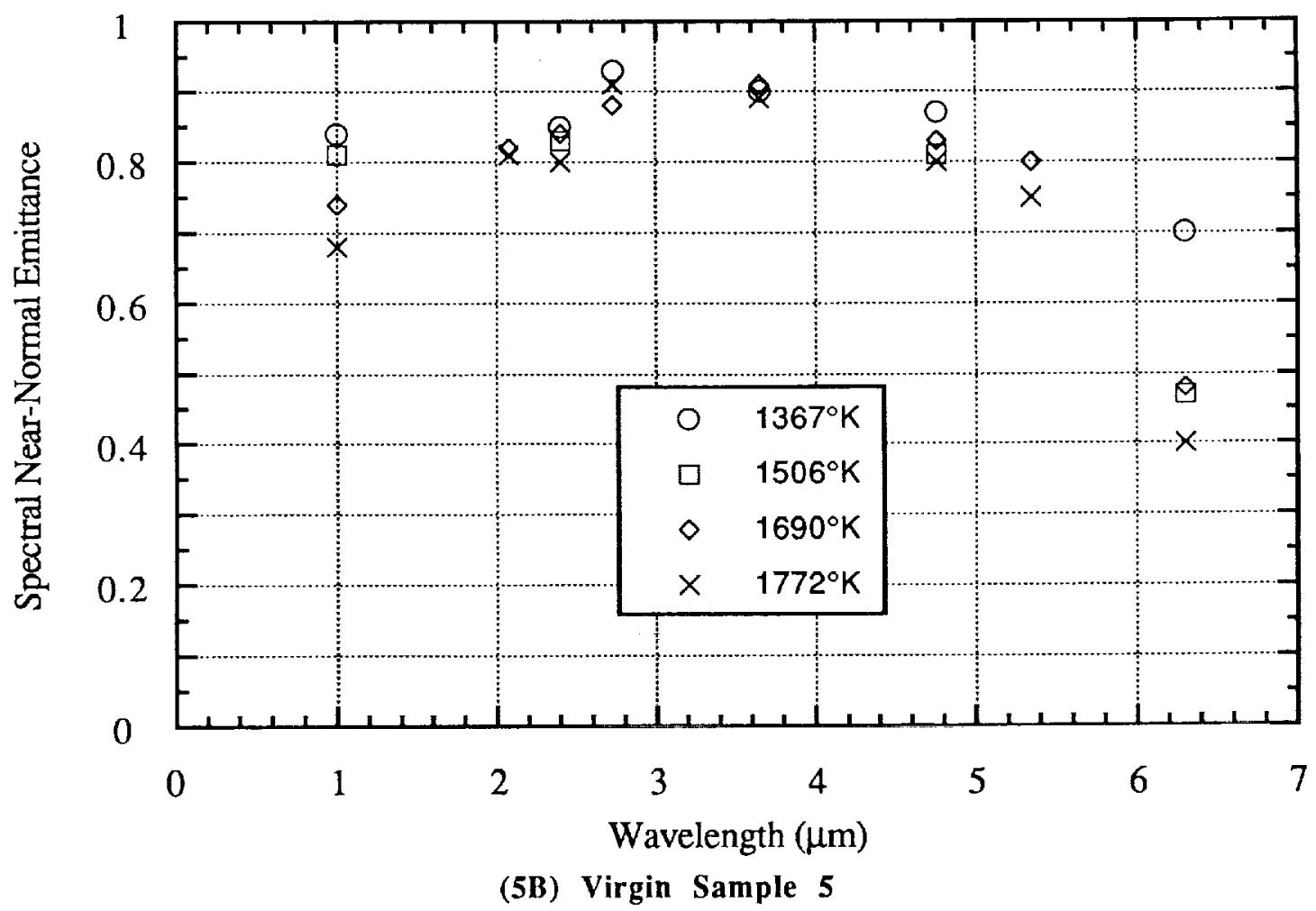

Figure 5 - High Temperature Near-Normal Spectral Emittance Data for Virgin RCC 


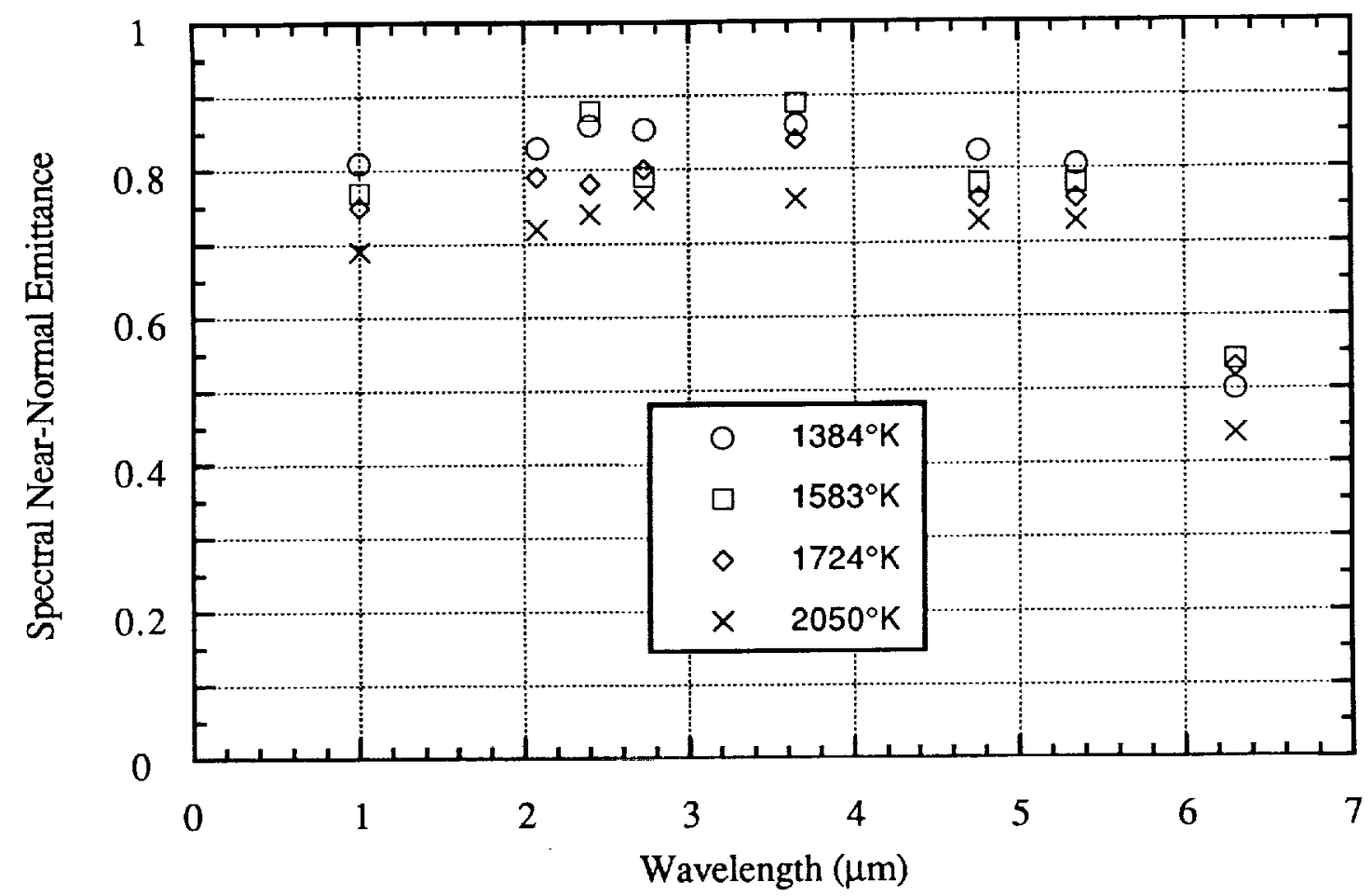

(6A) Flown RCC - Outer Surface - Sample 1

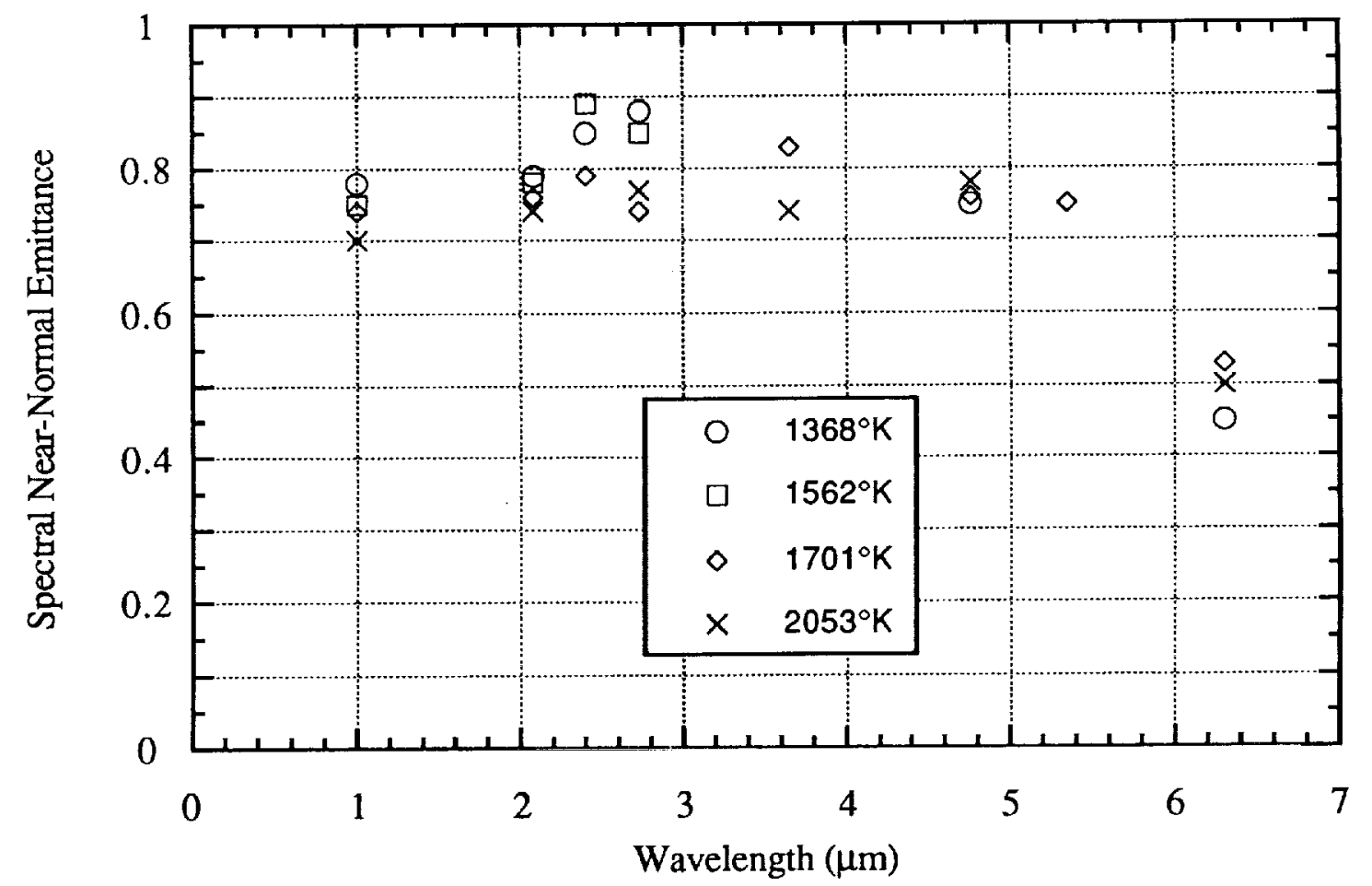

(6B) Flown RCC - Outer Surface - Sample 2

Figure 6 - High Temperature Near-Normal Spectral Emittance Data for Flown RCC 


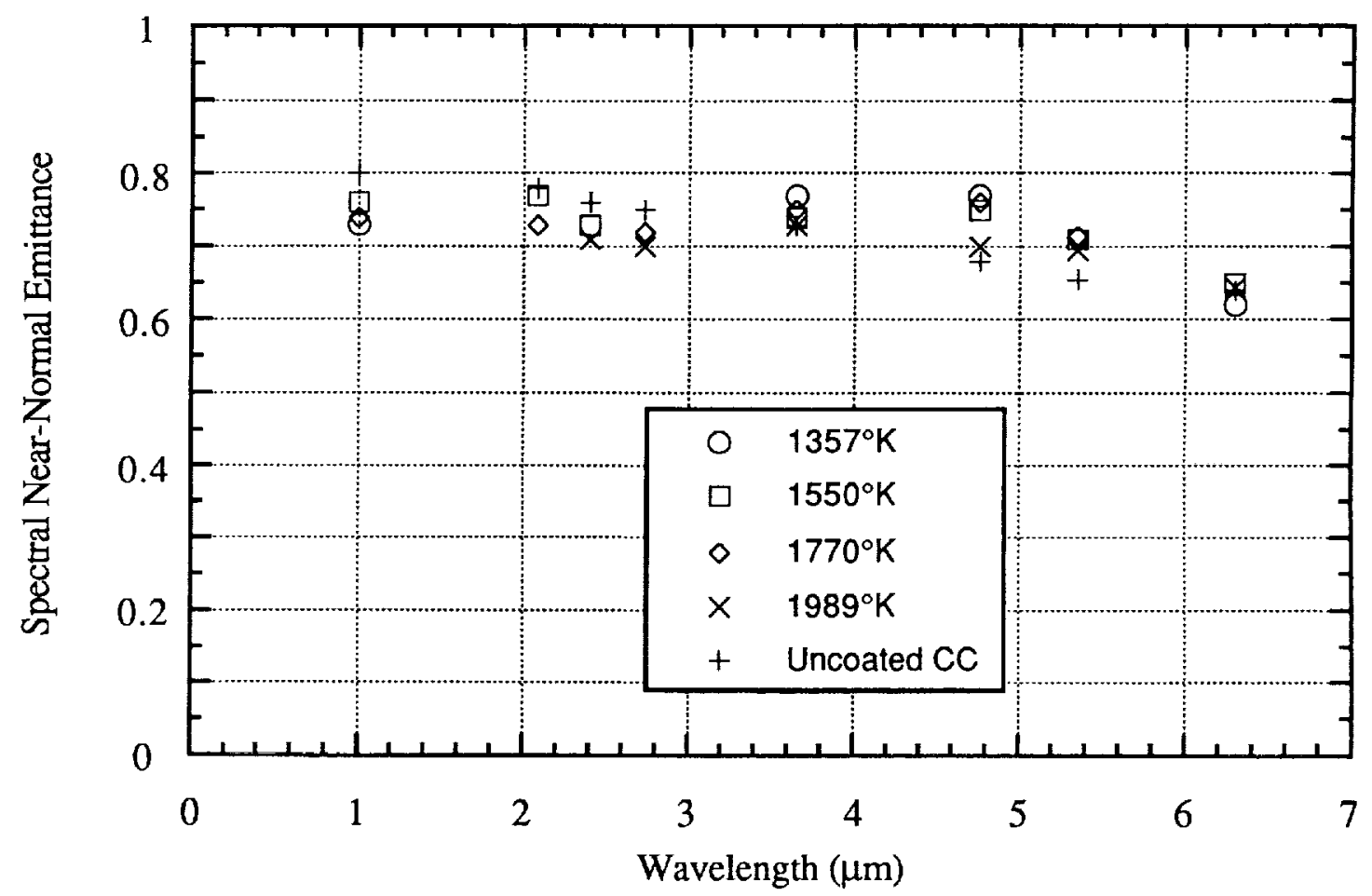

(7A) Flown RCC - Inner Surface - Sample 1

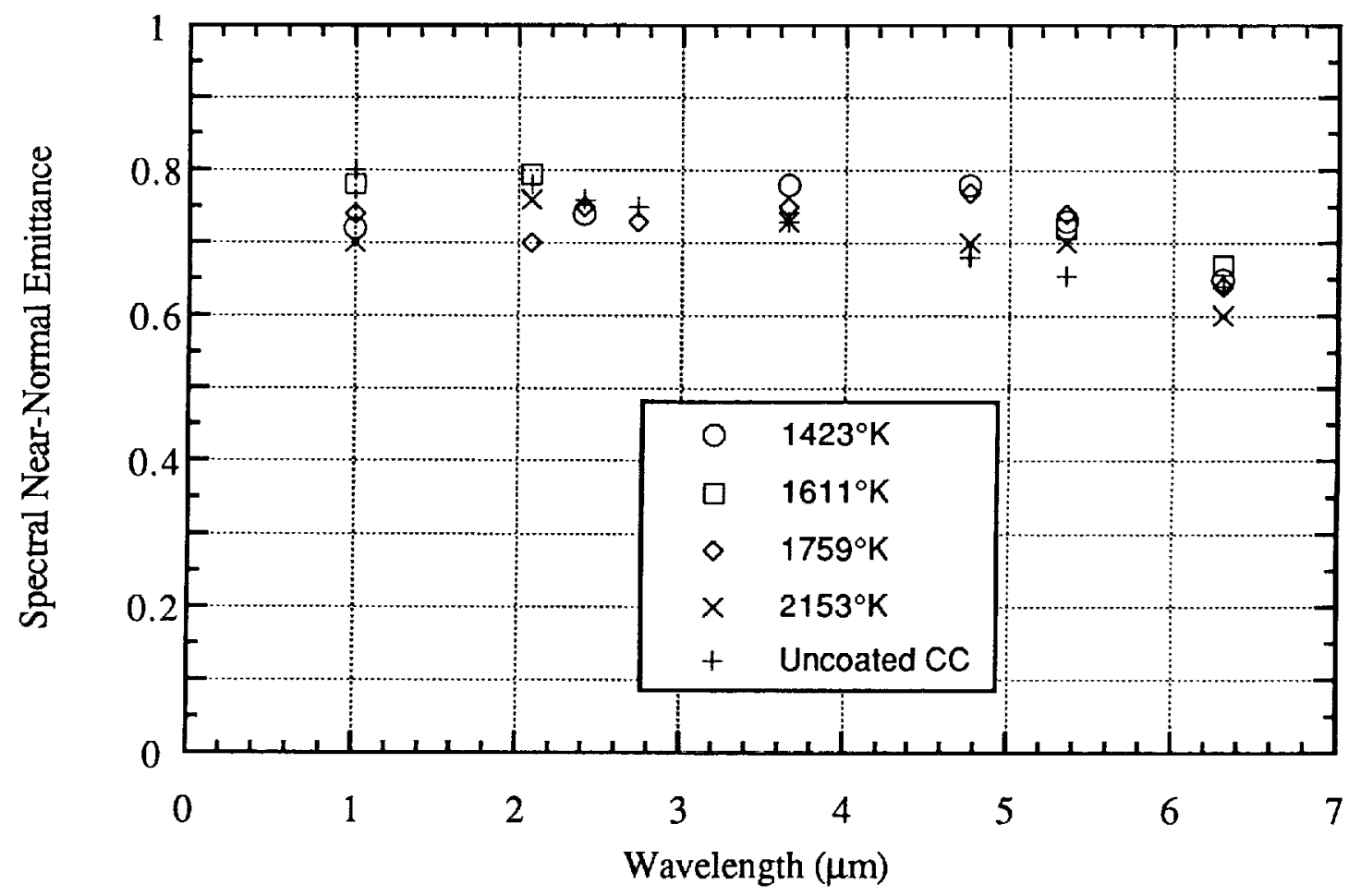

(7B) Flown RCC - Inner Surface - Sample 2

Figure 7 - High Temperature Near-Normal Spectral Emittance Data for Flown RCC 


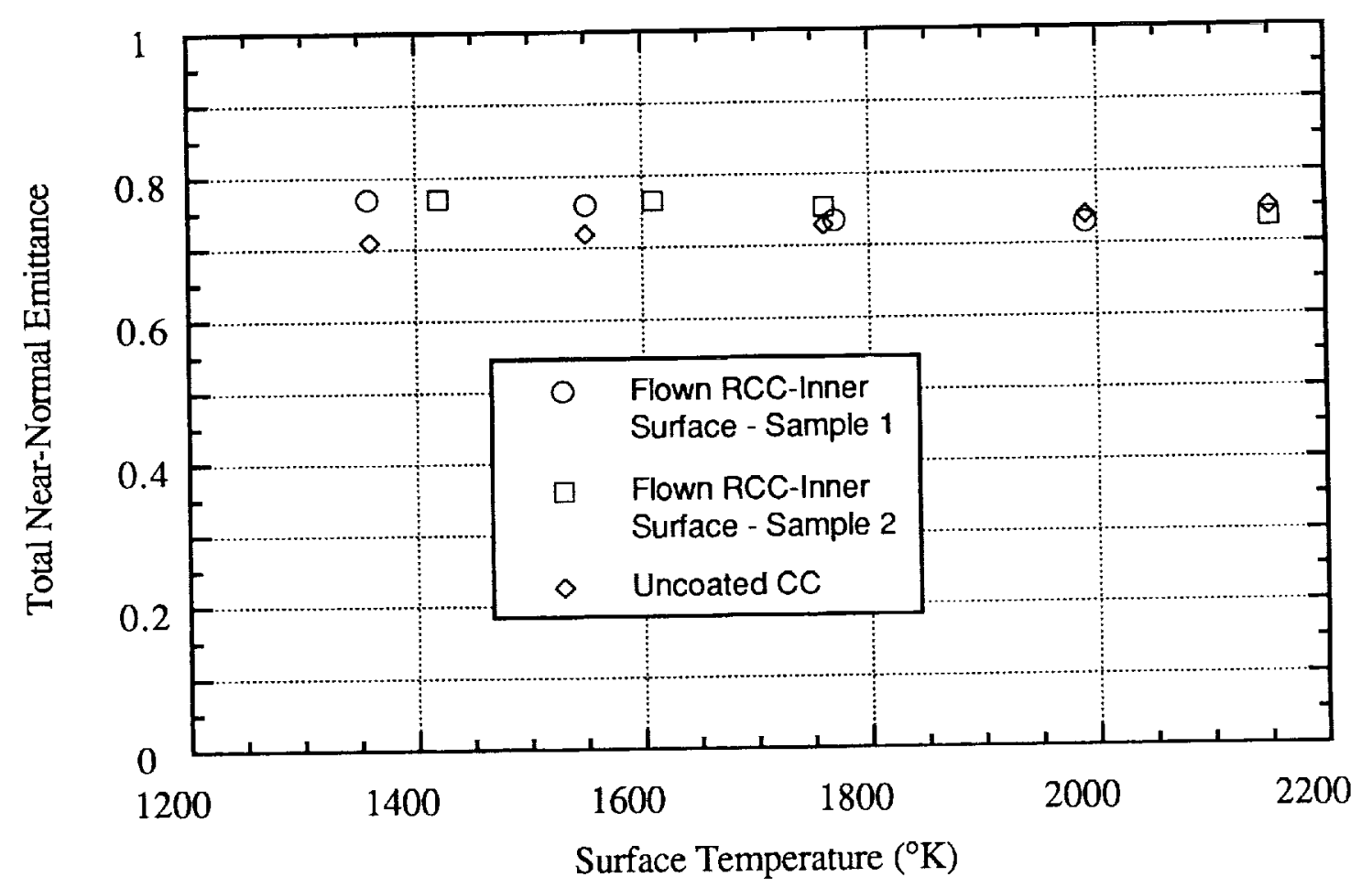

(8A) Flown RCC - Inner Surface

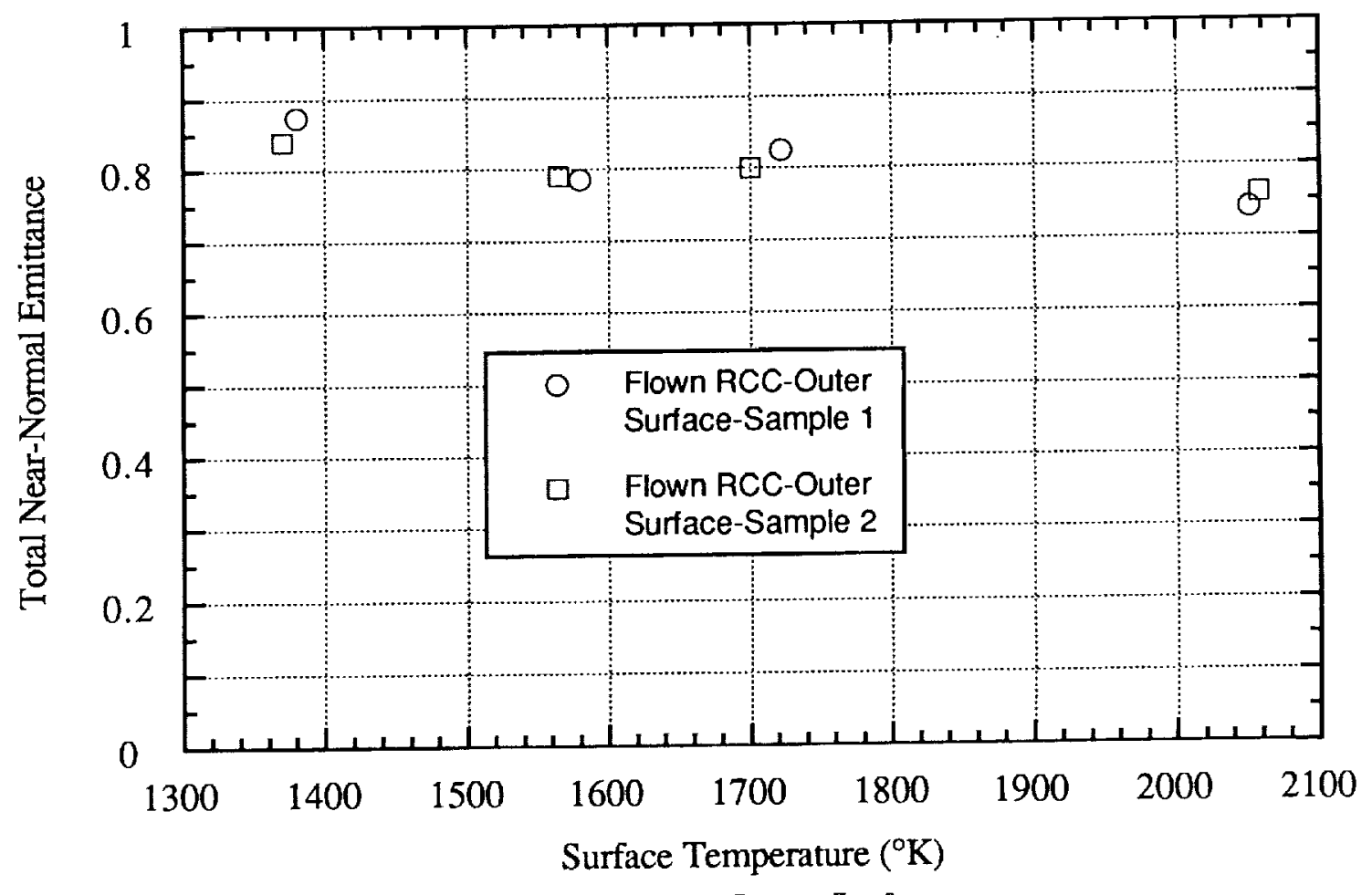

(8B) Flown RCC - Outer Surface

Figure 8 - High Temperature Total Normal Emittance Data for Flown RCC Samples 


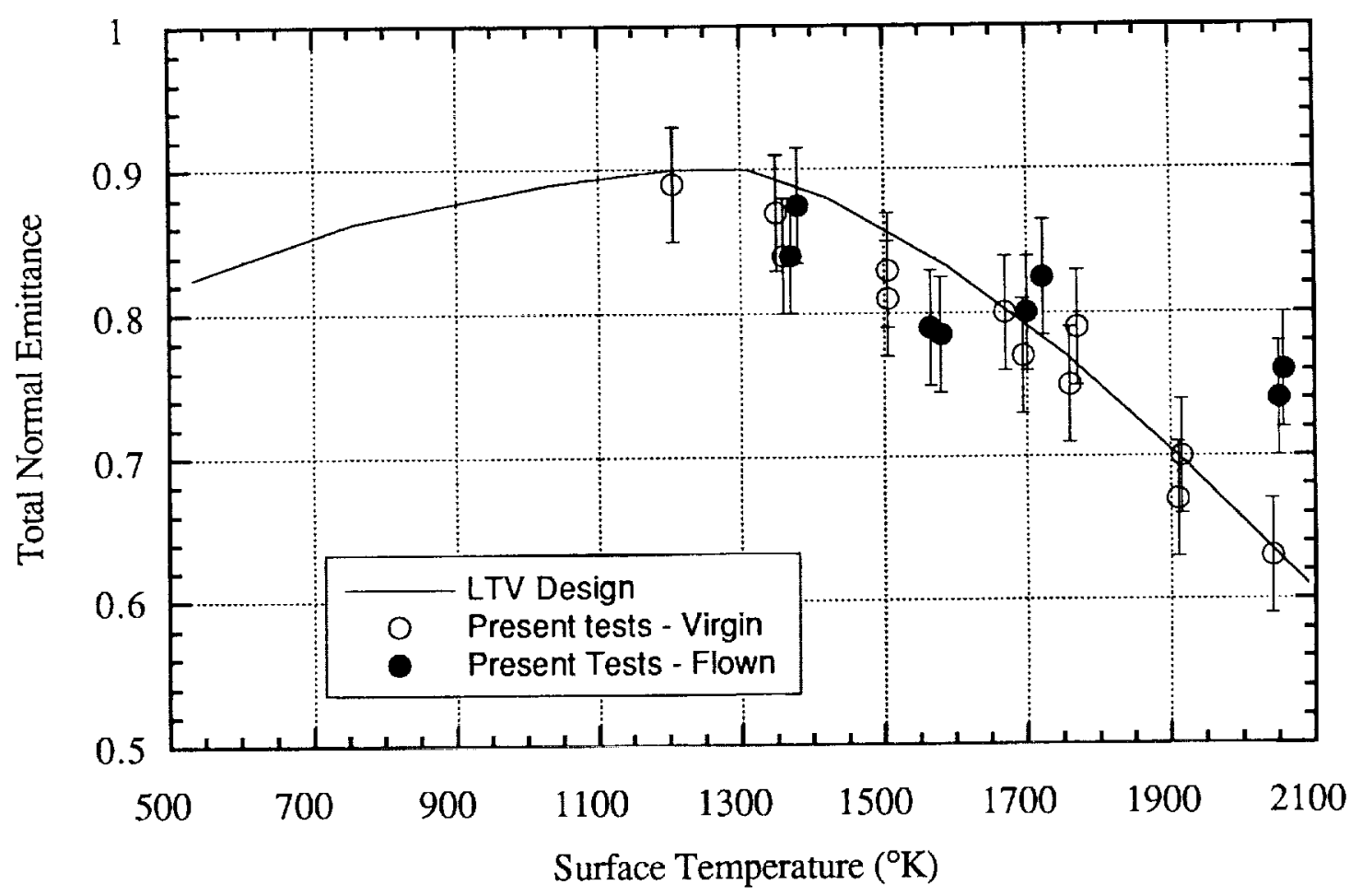

Figure 9 - Comparison of High Temperature Total Normal Emittance

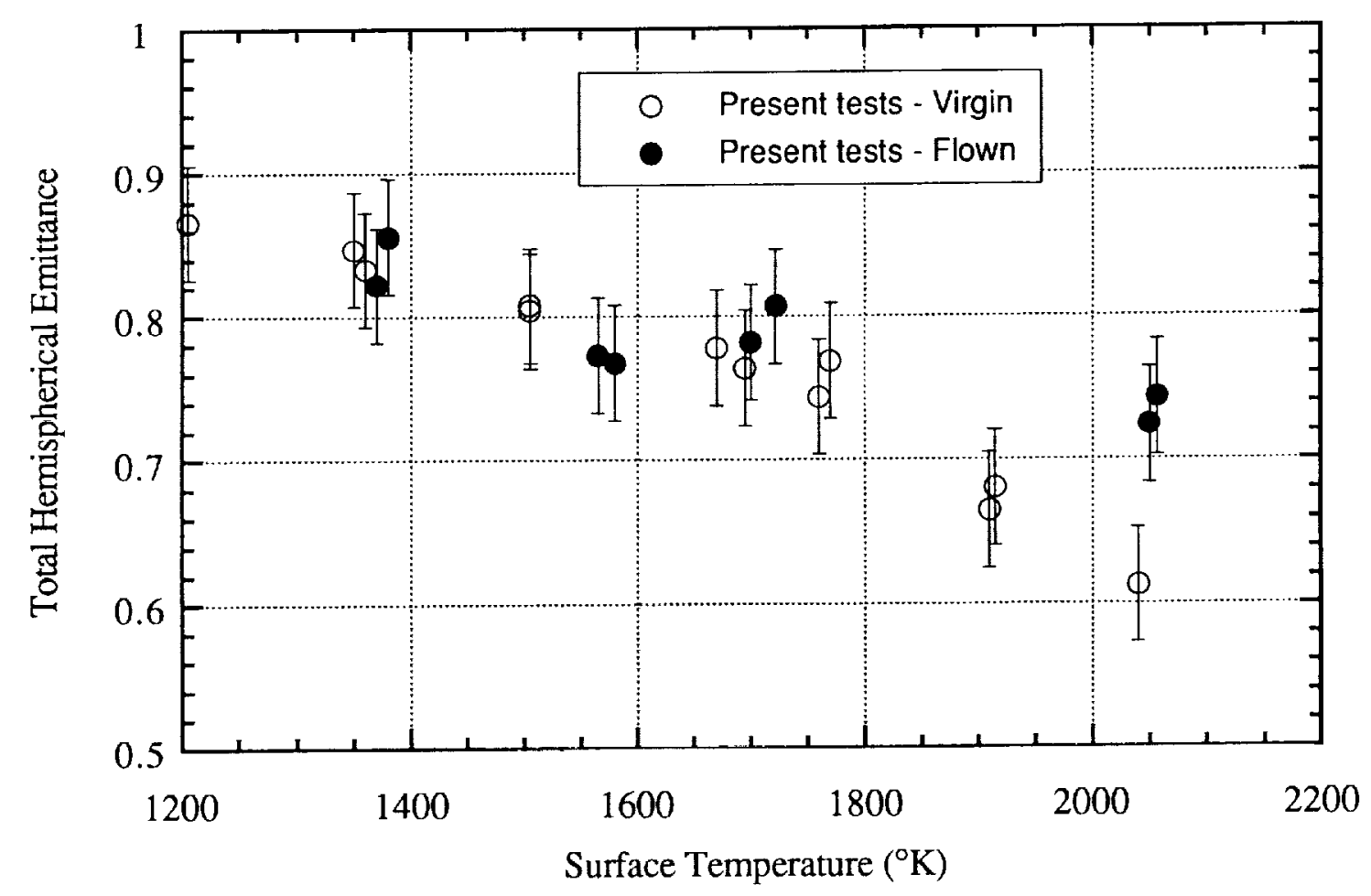

Figure 10 - Comparison of High Temperature Total Hemispherical Emittance 


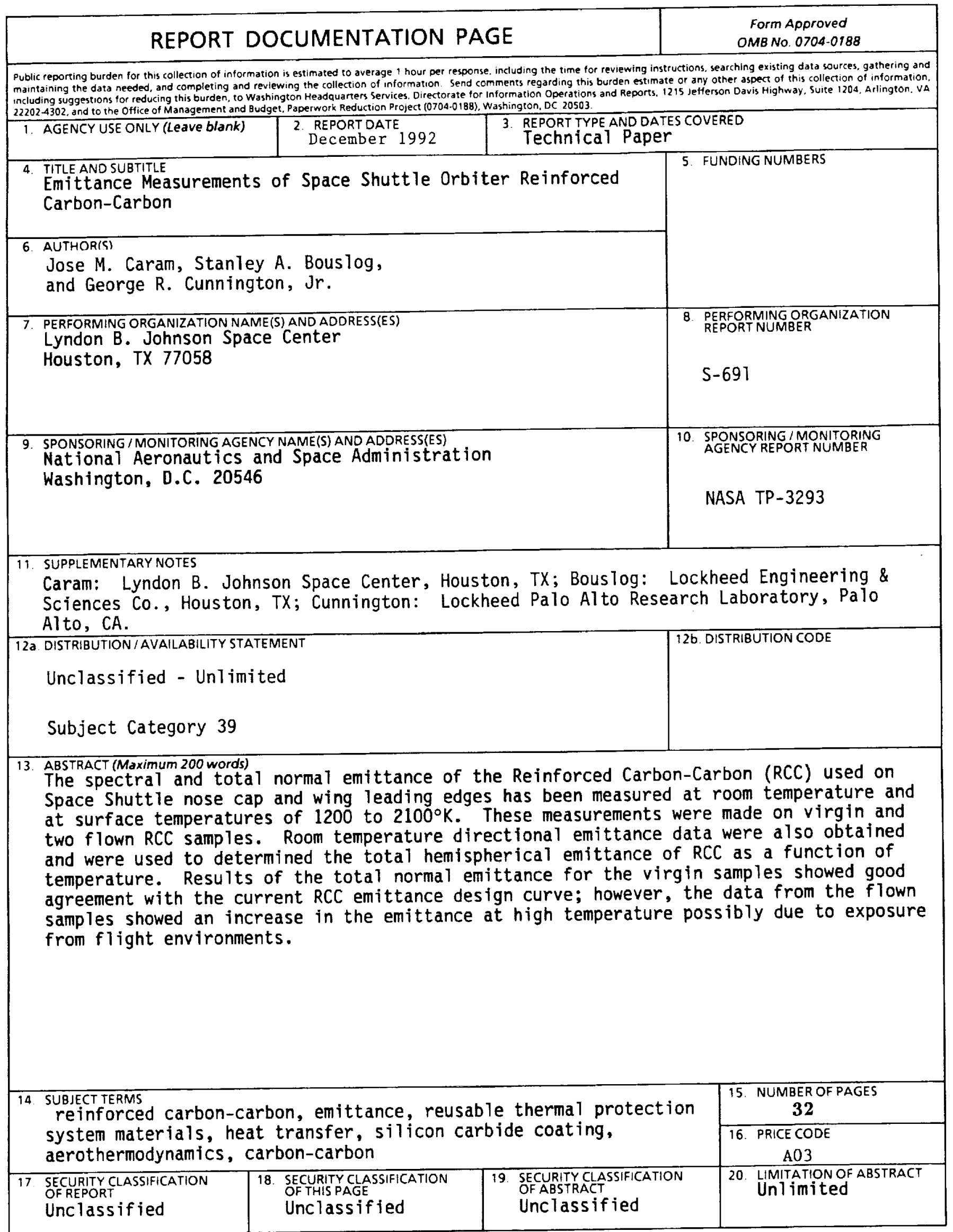

randard form 295 (Rev 2.89)

Preserbed by AN5! Sta 239.18

248.102 